\title{
Management control in multinational companies: a systematic literature review
}

\author{
Martina Sageder ${ }^{1,2}$ (D) Birgit Feldbauer-Durstmüller ${ }^{2}$
}

Received: 22 December 2016 / Accepted: 8 January 2018 / Published online: 22 January 2018 (C) The Author(s) 2018. This article is an open access publication

\begin{abstract}
Executing management control across borders is crucial for multinational companies (MNCs). Various management control mechanisms serve to align foreign subsidiaries with corporate goals. Management control at MNCs has been subject of numerous studies in the past 25 years, thus highlighting the relevance of the topic. To provide a comprehensive overview of the research field, a systematic literature review including 79 articles from scientific journals has been conducted that outlines various control mechanisms and presents underlying theories as well as development over time. The design of management control and management accounting depends on internal factors at headquarters and the subsidiary as well as on external factors like culture or market requirements. The relationship of headquarters with subsidiaries and the integration into the host country context represent another influence on management control. This paper categorizes influencing factors, discusses interactions and limitations of control mechanisms and suggests implications for practice and research along with avenues for future research.
\end{abstract}

Keywords Management control $\cdot$ Management accounting $\cdot$ Multinational company $\cdot$ MNC $\cdot$ Subsidiary control $\cdot$ Control system

JEL Classification M41 Accounting · F23 Multinational Firms

Martina Sageder

martina.sageder@fh-salzburg.ac.at

Birgit Feldbauer-Durstmüller

birgit.feldbauer-durstmuller@jku.at

1 Salzburg University of Applied Sciences, Urstein Süd 1, 5412 Puch, Austria

2 Institute of Management Control and Consulting, Johannes Kepler University, Altenberger Straße 69, 4040 Linz, Austria 


\section{Introduction}

Companies that establish international subsidiaries need to adapt to economic, political and other conditions in the respective host countries (Endenich et al. 2011) and have to overcome geographical and cultural divides to manage their operations (Dent 1996). Management control (MC) helps to align employee decisions and actions with corporate objectives (Chow et al. 1999). With increasing internationalization, companies face the challenge of transferring MC across national borders to distant subsidiaries (Harrison and McKinnon 1999). Multinational companies (MNCs) combine diverse mechanisms like planning, standardized procedures and training to control their foreign subsidiaries (Harzing and Sorge 2003). Various factors, either within or outside the company, influence the application and effectiveness of control mechanisms in MNCs.

MC of MNCs has been a research focus of numerous scholars in the past decades. Since the 1990s — with the breakdown of the Eastern Bloc and the rise of emerging countries in Eastern Europe and Asia-the complexity of multinational operations has increased which is clearly reflected in research (Kostova et al. 2016). In the last years the body of research has grown considerably; however, so far results are fragmented and partly contradictory. Extent literature reviews in relevant journals discuss specific insights such as headquarters-subsidiary relationships (e.g., Kostova et al. 2016), or analyze in detail the impact of individual factors like culture and its relevance for the design of management control systems (MCSs) (e.g., Harrison and McKinnon 1999) or explore specific regions (e.g., Hopper et al. 2009). Another field of research compares management accounting across regions (e.g., Endenich et al. 2011; Kuttner and Feldbauer-Durstmueller 2016). MNCs operate in various countries with widely differing characteristics and hence need to consider a broad set of influencing factors within and outside the company when designing their MCS. An overview of control mechanisms applied by MNCs and influencing factors, as well as their effects, has not yet been provided. This systematic literature review presents a comprehensive overview of control mechanisms in MNCs and discusses interactions between control mechanisms and a broad set of factors that impact $\mathrm{MC}$ in a multinational environment. To this end, 79 articles published over the past 25 years in a broad range of renowned scientific journals were analyzed. Findings from various research fields such as international management, accounting and organizational science are synthesized and insights from MNCs all over the world are presented. The study clusters factors that affect MC at multinational companies to create a common research base. We show the development of research findings over time, discuss contradictory results and summarize findings against the background of frequently applied theories. Finally, we outline implications for practitioners and researchers along with avenues for future research. This article is structured as follows: the subsequent section defines the theoretical framework, followed by an explanation of the methodology. Section 4 then provides an overview of the article characteristics and the applied theoretical frameworks. Sections 5 and 6 present the findings on control mechanisms and factors that influence MC at MNCs. A discussion of implications and limitations concludes the paper. 


\section{Theoretical framework}

\subsection{Multinational companies}

An MNC is characterized by geographically dispersed units whereby headquarters and subsidiaries are located in different countries. Each unit operates in the specific context of its host country and interacts with local business networks like suppliers or buyers within the legal and economic framework of the country, which influences the characteristics of the MNCs (Ghoshal and Bartlett 1990). MNCs are characterized by high complexity, which is also common with diversified and decentralized domestic companies. In addition to coordinating different business divisions, MNCs have to overcome geographical and cultural distances and need to adapt to the environment of the host country (Merchant and Van der Stede 2017). Foreign markets are entered either by establishing a wholly-owned subsidiary, acquiring an existing company or by forming a joint venture with a partner in the local market (Yiu and Makino 2002). Coordinating with a foreign partner adds complexity to managing and controlling non-domestic activities and therefore joint ventures represent a specific organizational context (Ding 1997). Studies on management control in joint ventures deal predominantly with the relationship between partners and the protection of their resource contributions, which this literature review does not focus on. Accordingly, findings that solely reference joint ventures are excluded.

\subsection{Management control and management control systems}

A broad variety of definitions exists for MC and MCS which are partly inconsistent (Chenhall 2003; Malmi and Brown 2008; Merchant and Otley 2007) and complicate the interpretation of research findings (Malmi and Brown 2008). Some concepts cover as wide a spectrum that almost all organizational practices are included in MCSs (Merchant and Otley 2007). For this literature review MC is defined according to Malmi and Brown (2008, p. 290) as "systems, rules, practices, values and other activities management put in place in order to direct employee behavior". MCSs consist of a range of such MCs and are "means of gathering and using information to aid and coordinate the planning and control decisions throughout an organization" (Horngren et al. 2012, p. 775). While strategic control focuses on the external environment and potentials compared to competitors, MC predominantly concentrates on internal activities that influence employee behavior according to predefined targets (Merchant and Van der Stede 2017).

MNCs employ various control mechanisms to coordinate units worldwide in order to meet global organizational objectives (Harzing and Sorge 2003). Despite the considerable number of definitions (Chow et al. 1999; Malmi and Brown 2008; Martinez and Jarillo 1991) a broad consensus exists on the meaning of output control in terms of achieving goals and results and comprising planning and reporting (Harzing 1999; Martinez and Jarillo 1991). Process controls specify desirable employee behavior and include centralization and standardization, as well as written manuals, to ensure that employees adhere to specified processes (Brenner and 
Ambos 2013). The last category encompasses a broad spectrum of mechanisms such as socialization, communication and training (Harzing 1999). According to Brenner and Ambos (2013) these formal and informal mechanisms are labeled social control and serve to spread corporate culture and values in order to build acceptance for other control mechanisms. The extent of control indicates the tightness of control an organization exerts to achieve its objectives, e.g., in terms of frequency, accuracy and combination of various MCs (Merchant and Van der Stede 2017).

\section{Methodology}

To investigate the current state of research on MC in MNCs, a systematic literature review was conducted in line with the guidelines suggested by Tranfield et al. (2003), who claim to increase the quality and transparency of such reviews by applying a systematic procedure of searching and selecting relevant literature. In the first step, the topic and corresponding keywords were defined by browsing key contributions on the subject. A list of selection criteria (see Table 1), the review protocol, as well as data extraction forms for the subsequent qualitative analysis, were prepared. In the next step, seven scientific databases (EBSCO, Sage, Science direct, Scopus, Springer, Web of Knowledge, and Wiley) were searched for the terms "manage* account*", "manage* control*, "control* system" in combination with "multinational" or "international". The search term "international" was complemented with "company", "corporation", "firm" and "enterprise" to limit the search results to relevant articles. Adding asterisks to the search terms ensured that variations such as "accounting" or "accountant" figured in the results. Duplicates were removed and the remaining articles were screened to verify the fit with the predefined criteria in Table 1. This review includes original contributions that analyze qualitative or quantitative empirical data (Senftlechner and Hiebl 2015) and present explicit findings for MC in MNCs. As the control of different business functions like R\&D or marketing requires a particular set of MC (Anthony et al. 2014; Chenhall 2003; Merchant and Van der Stede 2017) and hence represent highly specific research lines, articles that solely deal with the control of such business functions are excluded.

The search of the specified databases resulted in 1664 articles, of which 1588 were excluded, mainly due to duplicates (352), and lacking empirical findings for MC (609) or MNCs (199), publication before 1991 (114) or language (16). To ensure article quality, we relied on renowned international journal rankings and chose peer-reviewed articles from journals of a predefined standard. Therefore, all included articles had to be listed in the CABS Academic Journal Guide 2015 ranked 2 or higher or in VHB Jourqual 3 ranked C or higher (Bouncken et al. 2015; Sageder et al. 2018). This excluded another 298 articles. To minimize the risk of missing out on core contributions, references that were cited at least five times in the selected 76 articles were screened for their fit with the criteria defined in Table 1, which resulted in the inclusion of another three articles. Figure 1 illustrates the selection process.

The 79 articles that matched all defined criteria were included in the subsequent analysis. First, article characteristics like country of origin and research design were collected. Second, the empirical findings of the included articles were analyzed 
Table 1 Criteria for inclusion

\begin{tabular}{|c|c|c|}
\hline Characteristics & Inclusion criteria & Specification \\
\hline Language & English & \\
\hline Time-frame & 1991-2015 & \\
\hline Quality & $\begin{array}{l}\text { Included in CABS } 2015 \text { (ranking } \geq 2 \text { ) } \\
\text { or VHB-Jourqual } 3 \text { (ranking } \geq \mathrm{C} \text { ) }\end{array}$ & \\
\hline \multirow[t]{5}{*}{ Content } & Empirical research article & $\begin{array}{l}\text { Qualitative or quantitative data analysis: sur- } \\
\text { vey, archival data, case studies, interviews; } \\
\text { published full papers and research notes }\end{array}$ \\
\hline & MNC: & Exclusion: \\
\hline & $\begin{array}{l}\text { Headquarters and subsidiaries located } \\
\text { in different countries }\end{array}$ & $\begin{array}{l}\text { Management accounting education, banks, } \\
\text { joint ventures, franchise partners, services } \\
\text { for MNCs, comparative management } \\
\text { accounting studies without MNC context }\end{array}$ \\
\hline & MC: & Exclusion: \\
\hline & $\begin{array}{l}\text { MCS, budgeting, management } \\
\text { accounting, performance measure- } \\
\text { ment, control mechanisms, centrali- } \\
\text { zation, control of foreign subsidiaries }\end{array}$ & $\begin{array}{l}\text { external reporting, tax policy, internationali- } \\
\text { zation strategy, financing, capital markets, } \\
\text { control of specific business functions only: } \\
\text { R\&D, supply chain, HR, marketing }\end{array}$ \\
\hline
\end{tabular}

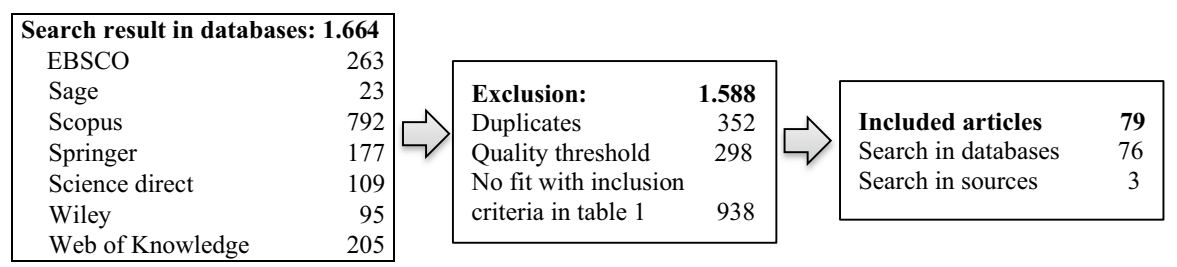

Fig. 1 Selection process

and categorized according to recurring themes within the articles (Bouncken et al. 2015).

\section{Article characteristics}

The majority of studies (36) investigate MNCs that originate from several different countries. Half of the studies (39) cover MNCs from Western countries like Europe and the US. 15 compare East-Asian and Western MNCs and eight examine East Asian MNCs. In 17 studies the headquarters' country of origin remain unspecified. In terms of subsidiaries the most thoroughly investigated regions are Europe (31), US (12), and China (9). 18 studies explore subsidiaries solely in emerging countries (including China); seven examine developed as well as emerging countries. Subsidiaries in emerging countries have been a research focus since the end of the 1990s with strong attention paid to East Asian countries (12), as well as occasional studies covering the Middle East (3), former Eastern Bloc countries (4), and Mexico (3). No 
contribution with focus on African or South American MNCs or subsidiaries could be identified.

The 79 articles of this literature review appeared in 45 scientific journals. Most articles were published in journals with international or management accounting focus. Management Accounting Research (13 articles), Accounting, Organizations and Society (5), Journal of International Management (5), International Business Review (4) and European Accounting Review (4) together published 39\% of the included articles. Some of the selected articles influenced other studies in this field. The eleven articles that were cited at least five times by other contributions within our review are presented in Table 2.

O'Donnell (2000) explores a model of foreign subsidiary control based on the interdependence of subunits. Chow et al. (1999) investigate the effects of national culture on MC and provide arguments for ten articles within the selection. Martinez and Jarillo (1991) search connections between strategy and use of control mechanisms. Eight studies rely on quantitative research designs, Busco et al. (2008), and Quattrone and Hopper (2005) gain insights from case studies. Hassel (1991) combines quantitative data with qualitative interviews. Unsurprisingly, older sources are cited more frequently, the latest source dates back to 2008.

As shown in Table 3, quantitative as well as qualitative research designs were used to investigate control in MNCs. 23 case studies, of which twelve examine one

Table 2 Most cited articles within selection

\begin{tabular}{lcl}
\hline Article & Cited & Topic \\
\hline O’Donnell (2000) & 13 & Foreign subsidiary control and interdependence \\
Chow et al. (1999) & 10 & Effects of national culture on MC \\
Martinez and Jarillo (1991) & 10 & Strategy and control mechanisms \\
Hassel (1991) & 7 & Performance measures in dynamic environments \\
Andersson and Forsgren (1996) & 6 & Impact of subsidiary embeddedness on MC \\
Busco et al. (2008) & 6 & Role of performance measurement in an MNC \\
Chang and Taylor (1999) & 6 & Effects of size, nationality and ownership on MC \\
Quattrone and Hopper (2005) & 6 & Implementation of information systems \\
Chung et al. (2000) & 5 & Relation between management style and MC \\
Roth and O'Donnell (1996) & 5 & Incentives in foreign subsidiaries \\
Kihn (2007) & 5 & Performance evaluation of subsidiary managers \\
\hline
\end{tabular}

Table 3 Research designs

\begin{tabular}{lclc}
\hline Quantitative design & Articles & Qualitative design & Articles \\
\hline Survey & 35 & Case study & 23 \\
Archival data & 2 & Interviews & 9 \\
Survey + archival & 3 & Case + interviews & 1 \\
Combination of quantitative + qualitative methods: 6 articles \\
\hline
\end{tabular}


single case, investigate control mechanisms and influencing factors in detail and allow profound insights into internal processes and developments.

The 35 quantitative surveys confirm various variables like headquarters nationality or cultural distance. Six studies combine quantitative and qualitative methods. Eight studies are longitudinal and document the development of MC over time. An overview over the research design of all included articles can be found in the "Appendix". Studies that cover the manufacturing sector (40 articles) dominate the research field. Only two articles investigate service firms; two more studies compare services with other sectors. No contribution from the retail industry was available. The remaining 33 contributions explore MC in cross-sectional samples without analyzing industry differences; two do not disclose the industry.

All 79 papers examine at least one control mechanism; 60 papers explore the combination of two or more control mechanisms. As shown in Table 4, between 1991 and 1995 the included studies focused on output controls investigating predominantly performance measurement systems (PMS) and related incentives. Since the second half of the 1990s, process and social control have gained in importance-process control representing 74\% and social control 58\% of all included studies between 1996 and 2015. Between 2006 and 2010, onethird of all articles were published. Since 2011 - perhaps triggered by the persisting financial crisis-the focus on output control has increased considerably. However, also the importance of process (72\%) and social controls (61\%) has remained stable.

In the last 25 years, a wide range of influencing factors on MC has been explored. Most of the included articles (77 out of 79) examine at least one influencing factor, 65 articles include 2 or more factors. The subsidiary's environment (43), the relationship between headquarters and subsidiaries (41) and MNC characteristics (40) are investigated most frequently. During the 1990s headquarters nationality (7) and cultural distance between headquarters and subsidiaries (6) were the predominantly researched influencing factors. Since the end of the 1990s, MNC characteristics, in particular the degree of internationalization (12), strategy (11) and corporate culture (10) have complemented headquarters nationality as most researched influencing factors. Moreover, the subsidiary environment, in particular culture (13) and environmental uncertainty (13), has increasingly gained research attention. We describe the development over time of mechanisms and influencing factors, subsequent to the respective chapters.

Table 4 Development of research focus on control mechanisms (multiple assignment of articles)

\begin{tabular}{lllllll}
\hline Period & $1991-1995$ & $1996-2000$ & $2001-2005$ & $2006-2010$ & $2011-2015$ & Total \\
\hline Output control & 6 & 13 & 7 & 21 & 17 & 64 \\
Process control & 2 & 13 & 8 & 20 & 13 & 56 \\
Social control & 1 & 9 & 7 & 15 & 11 & 43 \\
Extent of control & 3 & 4 & 0 & 6 & 6 & 19 \\
Total studies & 6 & 17 & 12 & 26 & 18 & 79 \\
\hline
\end{tabular}




\section{Control in MNCs}

\subsection{Mechanisms of control}

\subsubsection{Output control}

Output control prevails in research on MC at multinationals. PMS (23 studies) and linked incentives (16), budgeting (16), and reporting (13) are key issues. MNCs spread PMS worldwide to share strategies and goals and influence decisions of their subsidiaries (Busco et al. 2008; Dossi and Patelli 2008; Mahlendorf et al. 2012). Financial figures are widely used to measure performance (e.g., Abdallah and Alnamri 2015; Coates et al. 1995; Kihn 2008) due to their high acceptance and comparability across countries (Dossi and Patelli 2010; Kraus and Lind 2010; Moilanen 2008). These controls are scarcely adapted to country-specific conditions that subsidiaries are subjected to (Borkowski 1999; Kihn 2008). To comply with specific country requirements, subsidiaries develop performance measures to supplement the global PMS of the MNCs (Dossi and Patelli 2008; Moilanen 2007; Mongiello and Harris 2006). Non-financial measures often complement but do not replace financial figures (Dossi and Patelli 2010; Kihn 2008). The impact of alternative measures remains still low, when MNCs use Balanced Scorecard (BSC), which contains non-financial dimensions (Abdallah and Alnamri 2015; Kraus and Lind 2010). Frequently, non-financial measures relate to process and customer indicators (Chung et al. 2006; Dossi and Patelli 2010). Although non-financial measures are less standardized and therefore less accepted (Hassel 1991; Seal 2001), they help to compensate low controllability in volatile environments by integrating different performance perspectives (Dossi and Patelli 2010; Du et al. 2013).

PMS are frequently linked to incentives for aligning management decisions in subsidiaries with corporate goals (Al-Husan and James 2003; Mahlendorf et al. 2012; Roth and O'Donnell 1996). Incentives can be based on financial performance or refer to non-financial measures to extend the focus to long-term objectives (Coates et al. 1995; Dossi and Patelli 2010) and may integrate regional as well as corporate performance indicators (Roth and O'Donnell 1996). Monetary incentives for subsidiary managers are commonly linked to quantifiable measures, whereas career-related rewards are used to strengthen the identification of managers with the MNC (O'Donnell 2000). Conflicting findings exist on the effectiveness of incentives linked to PMS: While Dossi and Patelli (2010) find that incentives do not impact decisions taken in Italian subsidiaries, Mahlendorf et al. (2012) identify effects of reward mechanisms on subsidiary decisions in Chinese subsidiaries. On the basis of an international sample, Roth and O'Donnell (1996) report that subsidiary performance increases when managers' compensation and incentives consider cultural distance and the subsidiary's strategic positioning. Mahlendorf et al. (2012) refer to conceptual differences to explain these contradictory findings.

Reporting serves as a pillar of MC at foreign subsidiaries as it supports PMS and goals achievement (Chung et al. 2006; Cooper and Ezzamel 2013) and allows headquarters to gain insights into local business figures (Finnegan and Ni Longaigh 
2002; Seal 2001). Reliable and timely reporting from subsidiaries requires detailed process descriptions (Schaaper et al. 2011; Seal 2001) and some MNCs rely on expatriates to ensure direct reporting lines (Chang et al. 2009; Jaussaud and Schaaper 2006; Schaaper et al. 2011). MNCs frequently use integrated systems to achieve consistency in reporting (Al Chen et al. 1997; Hyvönen et al. 2008; Moilanen 2008). Hence, efficient reporting requires a coordinated approach of different control mechanisms.

Budgeting and budgeting controls are highly relevant for controlling foreign subsidiaries (Hassel and Cunningham 1996; Moilanen 2008; Van der Stede 2003) and often represent the basis for PMS (Busco et al. 2008; Frow et al. 2005; Moilanen 2008) and incentives (Van der Stede 2003). Budgeting processes draw on communication and information flows between headquarters and subsidiaries. Such complex budgeting processes raise the question whether a subsidiary's accountabilities should be aligned with budget-based performance measures. (Busco et al. 2008; Frow et al. 2005). Unlike the previously mentioned output controls, budgeting seems to be strongly affected by the background of the respective country, in particular regarding the importance of budgeting and the level of detail (e.g., Hoffjan et al. 2012; Keplinger et al. 2012; Moilanen 2007). The participation of subsidiaries in the budgeting process seems to enhance the commitment of a subsidiary's management to budgets (Frucot and Shearon 1991; Hassel and Cunningham 2004).

The research focus on output controls has changed over time. In the 1990s studies on PMS and incentives concentrated on financial performance indicators (Borkowski 1999; Coates et al. 1992; Hassel 1991). Studies conducted after 2000 focus on the effects of PMS and incentives on subsidiary decisions (Dossi and Patelli 2010; Mahlendorf et al. 2012), knowledge transfer (Busco et al. 2008; Chang et al. 2009), strategy implementation (Busco et al. 2008; Dossi and Patelli 2010; Hoque and Chia 2012) and the relationships between subsidiaries and headquarters (Dossi and Patelli 2008; Masquefa 2008). Similarly to PMS, budgeting has been a research focus over the whole period. In the beginning, effects of budgeting on financial performance were a key issue (Al Chen et al. 1997; Frucot and Shearon 1991; Hassel and Cunningham 1996). Later studies cover the controllability of budget-relevant conditions (Busco et al. 2008; Fernandez-Revuelta Perez and Robson 1999; Frow et al. 2005) and the influence of culture (e.g., Hoffjan et al. 2012; Keplinger et al. 2012; O'Connor et al. 2011). In the 1990s, aspects like headquarters nationality (e.g., Al Chen et al. 1997; Coates et al. 1992), cultural distance (e.g., Frucot and Shearon 1991; Hassel and Cunningham 1996) or environmental uncertainty (e.g., Borkowski 1999; Hassel 1991) were identified as determining factor. Newer studies confirm these factors (e.g., Dossi and Patelli 2010; O'Connor et al. 2011) and complement internal contingencies like strategy (Busco et al. 2008; Cools et al. 2008; Seal 2001) or degree of internationalization (Dong et al. 2008; Mongiello and Harris 2006; O'Connor et al. 2011). Findings on output control are based on quantitative as well as qualitative studies. Cultural effects on budgeting practices, however, are reported predominantly from qualitative studies. 


\subsubsection{Process control}

56 articles examine the relevance of process controls with a focus on centralization (30 articles), rules and process standardization (20) and decision rights (19). A centralized management style strives to intensely monitor operational business in order to inform decision makers at headquarters (Kranias 2000; Quattrone and Hopper 2005). Centralized MNCs place high emphasis on the transfer of the corporate culture to the subsidiaries (Al-Husan and James 2003; Williams and van Triest 2009). Introducing management information systems allows permanent information flow, which is essential for a centralized coordination of MNCs (Chang et al. 2009; Hyvönen et al. 2008; Schaaper et al. 2011). These systems allow real-time monitoring and coordination worldwide, which either reinforce centralization tendencies (Finnegan and Ni Longaigh 2002; Hyvönen et al. 2008; Quattrone and Hopper 2005) or strengthen local responsiveness (Al-Husan and James 2003; Finnegan and Ni Longaigh 2002; Quattrone and Hopper 2005). The consideration of local specifics like language or legal requirements is key to launching such systems in foreign subsidiaries successfully (Avison and Malaurent 2007; Sheu et al. 2004). Strategic decisions and capital expenditures are prone to be centralized (e.g., Al-Husan and James 2003; Finnegan and Ni Longaigh 2002; Moilanen 2008). Particularly, global transfer pricing policies - in some cases triggered by tax compliance requirements-appear to reduce the autonomy of subsidiaries (Cools et al. 2008; Cools and Slagmulder 2009; Plesner Rossing 2013). As transfer prices influence the performance of subsidiaries, PMS need to be adapted to avoid demotivation and dysfunctional behavior of managers (Borkowski 1999; Busco et al. 2008; Cools and Slagmulder 2009).

A certain degree of autonomy seems to exist for subsidiaries to react to local market requirements (Busco et al. 2008; Epstein and Roy 2007; Mongiello and Harris 2006). Within defined boundaries, local subsidiary managers have decision rights for the operational business (Al-Husan and James 2003; Finnegan and Ni Longaigh 2002; Neves and Bugalho 2008). While Taylor (1999), Kranias (2000) and Al-Husan and James (2003) find that shared values support the transfer of decision rights to subsidiaries, Williams and van Triest (2009) describe that shared values are associated with less decentralization. Taylor (1999) and Kranias (2000) investigate MNCs with Japanese headquarters, Al-Husan and James (2003) report on subsidiaries of French MNCs, all with a case study design. Williams and van Triest (2009) employed a quantitative survey design that included 50\% US-headquartered MNCs, which tend to be more centralized. Diverging findings could stem from different research designs, lower emphasis on social control in US MNCs or developments over time.

Most MNCs rely on written manuals, standardized procedures, and job descriptions, to control employee behavior in foreign subsidiaries (Al-Husan and James 2003; Jaussaud and Schaaper 2006; Moilanen 2008) for coordination and efficiency purposes and to ensure adherence to reporting requirements (Moilanen 2008; Schaaper et al. 2011). However, the efficiency of process control seems limited when it hinders flexibility (Cools and Slagmulder 2009; Plesner Rossing 2013; Richards and $\mathrm{Hu} 2003)$. 
Process controls were given little importance in early studies, but have constantly been investigated since the late 1990s in qualitative as well as quantitative studies. Articles on centralization and decision rights were published predominantly between 1999 and 2009. Since 2002 the introduction of management information systems has been in the focus of interest, contributing eleven articles. This research field has been explored only with qualitative research designs. Early papers discuss implementation problems that occur due to diverse cultures, languages or skills (Avison and Malaurent 2007; Moilanen 2007; Sheu et al. 2004). These issues seem to have lost their relevance after 2007 and disappeared from research once management information systems were routinely implemented in MNCs. The introduction of such systems shows two main effects: On the one hand, it facilitates control of worldwide activities and reduces information asymmetries between headquarters and subsidiaries through monitoring and standardization. On the other hand, it limits decision rights of subsidiary managements and strengthens centralization tendencies (e.g., Finnegan and Ni Longaigh 2002; Quattrone and Hopper 2005). For process control, again, headquarters nationality (e.g., Chow et al. 1999; Van der Stede 2003) and environmental uncertainty (e.g., Gencturk and Aulakh 1995; Mongiello and Harris 2006) have been in the focus of research. Cultural distance (e.g., Crespo et al. 2014; Richards 2000) and interdependence between business units (e.g., Du et al. 2013; Martinez and Jarillo 1991) seem equally important for explaining process control. By the end of the 1990s, the legal and political environment gained increasing attention in qualitative studies. Contributions discuss the legal and political influences in emerging countries (Beard and Al-Rai 1999; Moilanen 2007; Taylor 1999); other studies focus on tax compliance requirements in the US and Europe leading to corporate transfer pricing policies (Cools et al. 2008; Cools and Slagmulder 2009; Plesner Rossing 2013).

\subsubsection{Social control}

Applying formal and informal social controls is subject of investigation of 43 studies. 19 studies examine different forms of communication and collaboration. Further, the roles of expatriates (19) and training (10) for controlling foreign subsidiaries are explored. Social control mechanisms like training, informal communication and meetings help to initiate a performance-based culture at a subsidiary (Al-Husan and James 2003; Hoque and Chia 2012; Moilanen 2007), convey corporate values (Chung et al. 2000; Gencturk and Aulakh 1995; Harzing 2001) and pave the way for process and output controls (Brenner and Ambos 2013; Martinez and Jarillo 1991). Networks, which may be reinforced by expatriates, enhance communication within an organization (Brenner and Ambos 2013; Harzing 2001; Wilkinson et al. 2008). Regular communication ensures employee commitment to reporting procedures (Brenner and Ambos 2013; Moilanen 2007) and facilitates knowledge transfer between units (Cooper and Ezzamel 2013; Crespo et al. 2014; Lovett et al. 2009; Seal 2001). Moreover, communication enables the implementation and reinforces the efficiency of PMS (Hoque and Chia 2012; Moilanen 2007, 2008). Informal relationships that base on trust complement formal agreements and support change processes (Frow et al. 2005; Masquefa 2008; Seal 2001). In budgeting processes, 
communication between subsidiaries and headquarters allows for exchanging information about changes in the market with positive effects on performance (Hassel and Cunningham 1996, 2004).

MNCs employ expatriate managers to reform corporate culture (Al-Husan and James 2003; Brenner and Ambos 2013; Harzing 2001) in order to transfer knowledge to subsidiaries (Chung et al. 2000; Jaussaud and Schaaper 2006; Moilanen 2008) and to ensure reporting and performance monitoring, as well as compliance with corporate practices and procedures (Chang et al. 2009; Chung et al. 2006; Harzing 2001). Expatriate managers hold also positions on the management board with extensive control and coordination responsibilities (Du et al. 2015). Hence, expatriates perform output and process control tasks besides social control. Employing a high number of expatriates as a means of control indicates that headquarters execute tight subsidiary control (Chung et al. 2000; Neves and Bugalho 2008; Richards 2000). Despite the associated high costs, expatriates are a widespread mechanism of social control (Chung et al. 2006; Schaaper et al. 2011). Though, only expatriates with appropriate knowledge of the host country culture contribute positively to MC at foreign subsidiaries (Paik and Sohn 2004). Similarly to expatriates, the board of subsidiary directors assumes a predominantly coordinating role by transferring information between headquarters and a subsidiary. Moreover, it participates in the strategy formulation, monitoring and performance evaluation (Du et al. 2015).

Trainings are organized to convey skills and knowledge and to ensure that control mechanisms are applied appropriately in a multinational setting (Hoque and Chia 2012; Jaussaud and Schaaper 2006; Moilanen 2007), which often goes hand in hand with the introduction of a management information system (Moilanen 2007; Sheu et al. 2004). Particularly, when entering a foreign country, trainings assist managers in building networks and spreading corporate values and strategies throughout the MNC (Al-Husan and James 2003; Brenner and Ambos 2013). To some extent, training substitutes expatriates for cost-efficiency reasons (Schaaper et al. 2011). Overall, social mechanisms seem to be used in a less targeted way than process or output control for monitoring foreign subsidiaries (Fee et al. 2011) and variations between MNCs in the application of these mechanisms are high (Martinez and Jarillo 1991). These findings are illustrated by Brenner and Ambos (2013), who identify a broad variety of social control depending on the age of a subsidiary.

During large parts of the 1990s social control mechanisms were little investigated. Since 1999 expatriates and the transfer of shared values have been studied as means of control. The importance of expatriate managers for controlling foreign subsidiaries has decreased over time, which is also reflected in the number of studies. While between 1999 and $200542 \%$ of all articles deal with expatriates, from 2011 to 2015 the share totals $17 \%$. Ten of the 19 studies include subsidiaries in emerging countries like China or Russia (e.g., Jaussaud and Schaaper 2006; Moilanen 2008; Taylor 1999). Since 2003, ten contributions have explored training as a control mechanism-often in the context of the implementation of output and process control-exclusively approaching the topic with qualitative research designs (e.g., Al-Husan and James 2003; Brenner and Ambos 2013; Sheu et al. 2004). Formal and informal communication has been studied consistently over the whole period, though often as a side effect of other control mechanisms, such as 
communication accompanying budgeting processes, PMS or the implementation of management information systems (e.g., Busco et al. 2008; Hassel and Cunningham 1996; Hyvönen et al. 2008).

\subsection{Extent of control}

The extent of control influences the ability of MNCs to pursue global strategies (Chang et al. 2009; Dong et al. 2008). MNCs combine several mechanisms to control the activities of their units and complement output and process control mechanisms with social controls to meet coordination requirements (Brenner and Ambos 2013; Gencturk and Aulakh 1995; Martinez and Jarillo 1991). A high emphasis on various control mechanisms is associated with superior performance (Kihn 2010; Lin 2014), particularly, when pooling process controls with output controls (Kihn 2007, 2010). Complementing output controls with process controls helps to reduce negative effects of geographical or cultural distance (Chang et al. 2009; Gencturk and Aulakh 1995; Moilanen 2008). The tightness of control depends on the degree of internationalization as well as on the necessity of local adaptation (Lin 2014; Martinez and Jarillo 1991). In general, MC is tighter when the importance of a subsidiary in terms of size or investment is high (Chang and Taylor 1999; Dong et al. 2008; Moilanen 2007; Taylor 1999), subsidiary performance is perceived as unsatisfying (Lovett et al. 2009; Richards 2000) or it is threatened by the competition in the market (Al-Husan and James 2003; O'Connor et al. 2011). In a nutshell, MNCs apply tighter control when a big deal is at stake.

\section{Factors influencing control mechanisms at MNCs}

\subsection{MNC characteristics}

A variety of MNC characteristics representing either demographic features or relating to strategy and corporate culture influence MC. The 40 studies on these factors are listed in Table 5.

A high degree of internationalization is related to tight control (Dong et al. 2008; Kihn 2010) with a strong emphasis on financial and non-financial output controls (Gencturk and Aulakh 1995; Kihn 2008, 2010). Highly internationalized firms rely on setting goals and evaluating performance (Fee et al. 2011; Kihn 2008; Mongiello and Harris 2006). Increasing geographical dispersion prompts the integration of non-financial controls (Kihn 2008; Mongiello and Harris 2006) and challenges management information systems not least due to the different locations of experts and operations across different time zones (Hyvönen et al. 2008; Sheu et al. 2004). In contrast to Gencturk and Aulakh's (1995) finding, that process control appears to be less relevant with increasing internationalization, Yu et al. (2006) suggest that international experience has a positive effect on process control. Kihn (2010) supports this by claiming that managers in highly internationalized firms put strong focus on all controls including process control. This deviance may root in the research design: 
Table 5 MNC characteristics

\begin{tabular}{|c|c|c|}
\hline Factor & No. & Sources \\
\hline $\begin{array}{l}\text { Degree of } \\
\text { internationalization }\end{array}$ & 12 & $\begin{array}{l}\text { Dong et al. (2008), Epstein and Roy (2007), Fee et al. (2011), Gencturk } \\
\text { and Aulakh (1995), Hyvönen et al. (2008), Kihn (2008, 2010), Mong- } \\
\text { iello and Harris (2006), Neves and Bugalho (2008), O'Connor et al. } \\
\text { (2011), Sheu et al. (2004) and Yu et al. (2006) }\end{array}$ \\
\hline Strategy & 11 & $\begin{array}{l}\text { Al Chen et al. (1997), Al-Husan and James (2003), Busco et al. (2008), } \\
\text { Carr and Tomkins (1996), Chang et al. (2009), Cools et al. (2008), } \\
\text { Cools and Slagmulder (2009), Cooper and Ezzamel (2013), Hoque and } \\
\text { Chia (2012), Lin (2014) and Seal (2001) }\end{array}$ \\
\hline Corporate culture & 10 & $\begin{array}{l}\text { Avison and Malaurent (2007), Chung et al. (2000), Dossi and Patelli } \\
\text { (2010), Fernandez-Revuelta Perez and Robson (1999), Hoque and Chia } \\
\text { (2012), Kihn (2010), Lin (2014), Seal (2001), Sheu et al. (2004) and } \\
\text { Van der Stede (2003) }\end{array}$ \\
\hline $\begin{array}{l}\text { Organizational } \\
\text { complexity (size, } \\
\text { diversification) }\end{array}$ & 9 & $\begin{array}{l}\text { Borkowski (1999), Brenner and Ambos (2013), Carr and Tomkins (1996), } \\
\text { Cooper and Ezzamel (2013), Epstein and Roy (2007), Harzing and } \\
\text { Sorge (2003), Kihn (2008, 2010) and Neves and Bugalho (2008) }\end{array}$ \\
\hline Industry & 6 & $\begin{array}{l}\text { Al-Husan and James (2003), Harzing and Sorge (2003), Mongiello and } \\
\text { Harris (2006), Richards (2000), Taylor (1999) and Williams and van } \\
\text { Triest (2009) }\end{array}$ \\
\hline Knowledge and skills & 5 & $\begin{array}{l}\text { Giacobbe et al. (2016), Masquefa (2008), Moilanen (2007), Paik and } \\
\text { Sohn (2004) and Seal (2001) }\end{array}$ \\
\hline
\end{tabular}

References with quantitative research design in bold

while Gencturk and Aulakh (1995) studied activities of US MNCs in the early 1990s, Kihn (2010) and Yu et al. (2006) published their studies more than 10 years later. Moreover, Yu et al. (2006) included emerging countries, where establishing rules and procedures provides the basis for MC. This is supported by the argument that, at an early internationalization stage, detailed rules and procedures serve to establish control systems from the home country at subsidiaries (Neves and Bugalho 2008). The strong focus on output controls associated with high internationalization is reported by quantitative studies throughout the whole period. Findings on nonfinancial and process controls originate mainly from the second half of the 2000s.

MC serves to align business goals (Cooper and Ezzamel 2013) and a subsidiary's investment decisions (Al Chen et al. 1997; Carr and Tomkins 1996) with global strategy. Management accounting supports the translation of strategy into specific local performance targets and secures conformity with global rules and procedures (Chang et al. 2009; Cooper and Ezzamel 2013). Local requirements need to be aligned with global strategy, otherwise conflicts between local and global goals with potential negative effects on performance are predetermined (Busco et al. 2008; Cools and Slagmulder 2009; Lin 2014). A new strategic focus impacts the MCS of a firm (Al-Husan and James 2003; Cooper and Ezzamel 2013; Hoque and Chia 2012; Seal 2001) and requires adapting the PMS, as well as reforming the corporate culture through training and communication (Al-Husan and James 2003; Hoque and Chia 2012). The influence of strategy has predominantly been reported in qualitative papers. In the 1990s the influence of corporate strategy on investment decisions was investigated (Al Chen et al. 1997; Carr and Tomkins 1996). Mainly since 2008, 
effects of strategy and strategic changes on PMS and corporate rules often accompanied by extensive communication have been in the focus (e.g., Cools et al. 2008; Cooper and Ezzamel 2013; Hoque and Chia 2012).

The corporate culture of the parent company shapes the design of MC (Van der Stede 2003). A parent's corporate management pattern may induce close monitoring or a decentralized management style, which allows for a certain degree of autonomy to achieve objectives (Lin 2014). Corporate culture influences an MNC's emphasis on performance measures (Chung et al. 2000; Dossi and Patelli 2010; Kihn 2010) or on strategy implementation to control subsidiaries (Chung et al. 2000; Hoque and Chia 2012; Seal 2001). Organizational culture encourages or hinders the involvement of management and staff in control processes (Fernandez-Revuelta Perez and Robson 1999; Seal 2001) and the implementation of management information systems (Avison and Malaurent 2007; Sheu et al. 2004). Articles investigating the effects of corporate culture on MC appeared after 1999. Recent quantitative studies confirm findings for effects on PMS and on centralization tendencies.

Complexity of MNCs is defined by the size of the organization, its product and geographical diversification (Epstein and Roy 2007). Large MNCs place more emphasis on financial output controls to evaluate performance than small MNCs, which also rely on non-financial controls (Borkowski 1999; Kihn 2008, 2010). Social control is affected by size as well: larger MNCs send more expatriate managers to foreign subsidiaries (Harzing and Sorge 2003). Large and highly diversified MNCs are more likely to implement global environmental standards and central evaluation of environmental performance (Epstein and Roy 2007). Small MNCs rather base control activities on financial planning and on personal control through the owners (Neves and Bugalho 2008). High diversification is suggested to relate to formalized planning processes as a means of communication between headquarters and divisions (Carr and Tomkins 1996) as documented in case studies. Although many studies use size as control variable, remarkably little insights exist on effects of an MNC's size on MC. It seems safe to say, that large MNCs rely on tight output control to coordinate their subsidiaries. Findings on small MNCs are scarce and can, therefore, not be generalized.

Although most studies in this review focus on manufacturing firms or study mixed samples, some industry-specific manifestations of control can be identified. The services industry seems to opt for decentralization, as opposed to manufacturing firms, in order to better react to market-specific requirements (Al-Husan and James 2003; Mongiello and Harris 2006; Williams and van Triest 2009). The automotive industry is more likely to establish a managing director that originates from the parent country, which indicates tight control; local adaptations are few (Harzing and Sorge 2003). Manufacturers of consumer goods enjoy a higher degree of autonomy (Richards 2000; Taylor 1999), are more likely to be run by host country managers and show more local adaptations (Harzing and Sorge 2003). Industry-specific findings are scarce, but consumer-oriented industries like consumer-goods and services seem to be controlled less centralized in order to adapt to local markets. In addition, the protection of knowledge might be less important there.

Cultural and local knowledge as well as managerial and technological skills are critical resources to establish control of foreign activities. Understanding a 
subsidiary's operations is a precondition for setting and monitoring targets (Giacobbe et al. 2016). Similarly, social control as executed by expatriates requires adequate cultural knowledge of the host country (Paik and Sohn 2004). Besides intercultural knowledge, the expertise of management accountants is an important factor for implementing control systems (Masquefa 2008; Moilanen 2007; Seal 2001). However, insights on knowledge and skills are scarce for MC in a multinational setting and are mainly derived from case studies.

\subsection{Environment in the country of origin}

The control mechanisms of an MNC are influenced by the environment at the country of origin as documented by 27 studies (see details in Table 6). 20 studies examine the nationality of the headquarters, which, to a certain extent, serves as a proxy variable for culture. The nationality of an MNC's headquarters affects the type of control that is exerted which is confirmed by the findings of both, qualitative as well as quantitative studies. For output control, country-of-origin effects are relatively low, as financial measures, in particular profitability, are important for all MNCs regardless of their national background (Chang and Taylor 1999; Chung et al. 2006; Coates et al. 1995).

MC in the UK and US contains certain parallels: A particularly strong emphasis on profit (Coates et al. 1992) and financial short-term measures are used to evaluate the performance of managers (Borkowski 1999; Coates et al. 1995). The financial orientation shown in early studies is confirmed by the more recent results of Chung et al. (2006). Besides culture, the short-term focus could be supported by strong capital market orientation in Anglo-Saxon countries. Pudelko and Tenzer (2013) found that US MNCs focus on finance and production to control subsidiaries whereby marketing aspects frequently complement the financial dimension (Coates et al. 1995;

Table 6 Environment in the country of origin

\begin{tabular}{|c|c|c|}
\hline Factor & No. & Sources \\
\hline Nationality and culture & 20 & $\begin{array}{l}\text { Al Chen et al. (1997), Al-Husan and James (2003), Borkowski } \\
\text { (1999), Carr and Tomkins (1996), Chang and Taylor (1999), } \\
\text { Chang et al. (2009), Chow et al. (1999), Chung et al. (2006), } \\
\text { Coates et al. (1992, 1995), Dossi and Patelli (2008, 2010), Du } \\
\text { et al. (2013), Harzing and Sorge (2003), Hoffjan et al. (2012), } \\
\text { Jaussaud and Schaaper (2006), O'Connor et al. (2011), Pudelko } \\
\text { and Tenzer (2013), Schaaper et al. (2011) and Williams and van } \\
\text { Triest (2009) }\end{array}$ \\
\hline Capital market orientation & 4 & $\begin{array}{l}\text { Carr and Tomkins (1996), Coates et al. (1992), Kraus and Lind (2010) } \\
\text { and Seal (2001) }\end{array}$ \\
\hline $\begin{array}{l}\text { Information and commu- } \\
\text { nication technology }\end{array}$ & 3 & $\begin{array}{l}\text { Finnegan and Ni Longaigh (2002), Hyvönen et al. (2008) and Wil- } \\
\text { liams and van Triest (2009) }\end{array}$ \\
\hline Legal framework & 3 & $\begin{array}{l}\text { Cools et al. (2008), Cools and Slagmulder (2009) and Plesner Rossing } \\
\text { (2013) }\end{array}$ \\
\hline
\end{tabular}

References with quantitative research design in bold 
Pudelko and Tenzer 2013). While social control of expatriates is of minor relevance (Chang and Taylor 1999; Pudelko and Tenzer 2013), US MNCs stress process control by imposing strict rules and procedures (Chow et al. 1999; Sheu et al. 2004). In addition, US MNCs seem prone to centralization, although they are willing to concede decision rights to their subsidiaries if required (Williams and van Triest 2009). Of 25 articles on MNCs headquartered in the US, nine explicitly describe nationality or national culture as influencing factor. The financial orientation is reflected in a relatively high number of contributions on PMS and incentives (10, 40\% of all studies). Eight articles (32\%) deal with centralization. The emphasis on social control $(8,32 \%)$ is relatively low compared to other regions. Short-term orientation, strong financial focus and lower relevance of social control as reported in early studies is also found in current research. Ten studies investigate MNCs originating from UK, of which five explore the influence of headquarters nationality in comparison to the US, Germany or Japan, and find that UK MNCs place their emphasis also on shortterm performance and financial metrics (Borkowski 1999; Carr and Tomkins 1996; Chung et al. 2006; Coates et al. 1992, 1995). Cost reduction is an important target, although innovation is also a priority (Borkowski 1999).

The focus and relative weight of non-financial measures vary between countries. German MNCs rather focus on internal business and customer measures than US and UK companies (Chung et al. 2006). This might indicate the long-term orientation of the former as suggested by Carr and Tomkins (1996), who found that German MNCs stress long-term orientation in investment decisions. German MNCs, moreover, include marketing aspects (Coates et al. 1995) as well as product and technological innovation measures when evaluating the performance of their subsidiaries (Borkowski 1999). Although still important, the weight attributed to financial measures is lower than in other regions (Borkowski 1999; Chung et al. 2006). Expatriates play a minor role for controlling foreign subsidiaries compared to Japanese MNCs (Pudelko and Tenzer 2013). Eleven studies investigate MNCs headquartered in Germany, six with explicit focus on nationality or culture. Basic characteristics of German MNCs appear stable over time.

Eleven studies deal with Finnish MNCs; none of them with focus on nationality of headquarters, though. There seems to be considerable interest in the application of financial and non-financial measures (7 studies) in this region. Control priorities in MNCs compared to other countries of origin are missing. French MNCs were subject of seven studies, of which only two explicitly address headquarters nationality. French MNCs tend to be centralized and rely on process controls (Schaaper et al. 2011). Al-Husan and James (2003) found diverse manifestations of centralization in Jordanian subsidiaries of two French MNCs, indicating a strong influence of corporate culture or other context factors. Budgets seem less important than in German corporations (Hoffjan et al. 2012). While former case studies indicate, that French MNCs use expatriates to control their foreign operations (Al-Husan and James 2003; Avison and Malaurent 2007), Schaaper et al. (2011) found that in recent years, the employment of expatriate managers has been replaced by training local staff mainly for cost reasons. Despite the common economic space and geographical proximity, MC in European MNCs is not homogenous (Harzing and Sorge 2003). So common insights are rare: European MNCs, tend to focus on innovation measures (Borkowski 
1999). Centralization tendencies appear to be weaker in European corporations than in US MNCs (Williams and van Triest 2009) and the use of expatriates seems common but to a lesser extent than in Japanese MNCs. European companies rather recruit and train local workforce (Jaussaud and Schaaper 2006; Pudelko and Tenzer 2013). 37 studies cover MNCs headquartered in Europe and investigate centralization $(13,35 \%)$ as well as PMS and incentives $(17,49 \%)$. While the introduction of management information systems is subject of seven European studies, this issue seems of minor importance for researchers in the US who contribute two case studies. Social control is investigated in 20 articles (54\%) and appears more relevant in Europe than in the US. As no current study comparing MNCs in Europe is at hand, the effects of recent developments like the European Single Market or harmonization of legal standards are unclear.

Compared to European headquarters, Taiwanese and Japanese headquarters place a strong emphasis on standardizing operations and exert intense process control by establishing rules and monitoring procedures (Chang et al. 2009; Jaussaud and Schaaper 2006), confirming the results of Chow et al. (1999), who found that Japanese and Taiwanese firms prefer high levels of process control, which, though, is even surpassed by US MNCs. Similarly to German MNCs, the focus on financial measures is weaker than in Anglo-Saxon countries (Borkowski 1999; Chung et al. 2006) with higher long term orientation (Borkowski 1999). Japanese MNCs strongly rely on expatriation for controlling foreign subsidiaries (Chung et al. 2006; Pudelko and Tenzer 2013; Schaaper et al. 2011). 23 articles investigate East Asian MNCs. with ten contributions (43\%) on centralization tendencies. More than $60 \%$ of studies deal with expatriates which reflects the importance of this research subject in this region. PMS and incentives seem to be of minor interest (6 studies, 26\%).

Although the national culture of the headquarters is frequently suggested to influence MC (Harzing and Sorge 2003; Pudelko and Tenzer 2013), there are only few studies that explicitly investigate the influence of the headquarters' national culture on control in foreign subsidiaries, mainly based on Hofstede's (2001) cultural dimensions. Culture appears to affect performance evaluation, e.g., the value of fairness in performance evaluation (Borkowski 1999) and the type of control that is exerted (Chang and Taylor 1999). Dossi and Patelli (2010) found that countries with low power distance, uncertainty avoidance and a highly individualistic culture use PMS more interactively and include more non-financial indicators, such as customer-oriented measures. This finding, however, is inconsistent with findings on US MNCs which are characterized by low power distance and individualistic culture but low integration of non-financial figures in PMS (Borkowski 1999; Williams and van Triest 2009). PMS appear to have more influence on subsidiary decisions if headquarters are located in a country with high scores on individualism, femininity, equality, and tolerance for uncertainty (Dossi and Patelli 2008). Cost accounting methods exhibit strong future orientation in Japan, where long-term orientation prevails, compared to short-term oriented MNCs in the US (Al Chen et al. 1997). Depending on the home country, controls adapt to a varying extent to local characteristics of the host country which may also root in the differences in national cultures of the host and home countries (Chow et al. 1999). Most findings in this section derive from quantitative studies, although some date back to the 1990s with 
lacking confirmation in actual studies, like the importance of fairness in PMS and adaptation to host country cultures.

MNCs from countries with high capital market orientation, e.g., the US and UK emphasize short-term financial indicators such as earnings per share to measure performance (Carr and Tomkins 1996; Coates et al. 1992). Capital market pressure prompts a focus on shareholder value and on financial indicators, which may conflict with other (non-financial) goals of the MNC (Kraus and Lind 2010; Seal 2001). Few studies from the US and Europe investigate the influence of capital market pressure on MC. Some of these findings date back to the 1990s. The importance of capital markets in Europe has changed considerably over the past 20 years (Kraus and Lind 2010), so findings might not be consistent over time. Moreover, quantitative evidence is lacking for this factor.

New developments in information and communication technologies enable subsidiaries to access data worldwide and headquarters to monitor operations and performance in real-time (Finnegan and Ni Longaigh 2002; Williams and van Triest 2009). This virtual integration allows for MC centralization, as headquarters can implement coordination (Finnegan and Ni Longaigh 2002; Hyvönen et al. 2008). In addition, social control reduces as IT systems can monitor compliance with global strategies and rules (Williams and van Triest 2009). Only case studies on the introduction of information systems between 2002 and 2009 report effects of new technologies on MC.

Legal frameworks, and above all accounting and tax regulations, influence corporate control systems. Tax authorities increasingly restrict flexibility of transfer prices to limit tax-minimizing behavior of MNCs. In the past decade, tax compliance has been reported as dominating criterion for setting transfer pricing within MNCs thereby undermining business aspects (Cools et al. 2008; Cools and Slagmulder 2009; Plesner Rossing 2013). Tax legislation and tax-optimizing policies on the group level entail far-reaching implications for MC. Above all, PMSs have to be adapted (Cools et al. 2008; Cools and Slagmulder 2009). Otherwise, restricted accountability may limit the motivation for innovative behavior at subsidiaries (Cools et al. 2008) and lead to suboptimal economic decisions (Cools and Slagmulder 2009) Standardized transfer prices are proposed to enhance the use of external benchmarks, increase internal transparency and promote non-financial performance indicators to adjust performance evaluation (Cools et al. 2008). Moreover, corporate transfer pricing fosters centralization and formalization at the expense of flexibility (Cools et al. 2008; Cools and Slagmulder 2009; Plesner Rossing 2013). Tax compliance issues have been researched in case studies since 2008, indicating considerable impacts on centralization and PMS.

\subsection{Relationships of subsidiaries within MNCs}

Several factors shape the relationship of subsidiaries with headquarters as well as other units. For an overview see Table 7.

Cultural and geographical distance between headquarters and subsidiaries complicate communication at MNCs (Beard and Al-Rai 1999; Crespo et al. 2014; Hassel 
Table 7 Relationship of subsidiaries within MNCs

\begin{tabular}{|c|c|c|}
\hline Factor & No. & Sources \\
\hline $\begin{array}{l}\text { Cultural and geo- } \\
\text { graphical distance }\end{array}$ & 22 & $\begin{array}{l}\text { Al-Husan and James (2003), Avison and Malaurent (2007), Beard and } \\
\text { Al-Rai (1999), Coates et al. (1995), Crespo et al. (2014), Frucot } \\
\text { and Shearon (1991), Giacobbe et al. (2016), Hassel (1991), Has- } \\
\text { sel and Cunningham (1996, 2004), Hoffjan et al. (2012), Jaussaud } \\
\text { and Schaaper (2006), Keplinger et al. (2012), Lin (2014), Moilanen } \\
\text { (2007, 2008), Neves and Bugalho (2008), Richards (2000), Roth } \\
\text { and O'Donnell (1996), Schaaper et al. (2011), Sheu et al. (2004) and } \\
\text { Wilkinson et al. (2008) }\end{array}$ \\
\hline $\begin{array}{l}\text { Interdependence } \\
\text { within MNC }\end{array}$ & 15 & $\begin{array}{l}\text { Andersson and Forsgren (1996), Busco et al. (2008), Chung et al. } \\
\text { (2000), Dong et al. (2008), Dossi and Patelli (2010), Du et al. (2013), } \\
\text { Frow et al. (2005), Gencturk and Aulakh (1995), Harzing (2001), } \\
\text { Harzing and Sorge (2003), Jaussaud and Schaaper (2006), Lin } \\
\text { (2014), Martinez and Jarillo (1991), O'Donnell (2000) and Taylor } \\
\text { (1999) }\end{array}$ \\
\hline Social relationships & 7 & $\begin{array}{l}\text { Brenner and Ambos (2013), Dossi and Patelli (2008), Fernandez-Revuelta } \\
\text { Perez and Robson (1999), Hyvönen et al. (2008), Masquefa (2008) and } \\
\text { Moilanen (2007, 2008) }\end{array}$ \\
\hline $\begin{array}{c}\text { Importance of } \\
\text { subsidiary }\end{array}$ & 3 & Chang and Taylor (1999), Dossi and Patelli (2010) and Moilanen (2007) \\
\hline
\end{tabular}

References with quantitative research design in bold

1991) and affect various mechanisms of MC. Cultural distance leads to a diverging understanding of control mechanisms which may cause resistance to control systems (Hoffjan et al. 2012; Keplinger et al. 2012; Moilanen 2007, 2008). In addition, increased cultural distance is associated with lower performance (Lin 2014). Lacking familiarity with the local culture limits the ability to exert control over foreign activities (Giacobbe et al. 2016; Paik and Sohn 2004) and impedes the implementation of management information systems (Avison and Malaurent 2007; Sheu et al. 2004). Low cultural distance enhances trust in a subsidiary's management, while high cultural distance intensifies controls (Moilanen 2008; Richards 2000). To incorporate the respective culture in the evaluation of foreign managers, MNCs use different incentive schemes for foreign and home operations (Coates et al. 1995; Roth and O'Donnell 1996) whereby the incentive proportion increases with cultural distance (Roth and O'Donnell 1996). Geographically dispersed units are predominantly controlled with financial performance measures-even in dynamic environments - as the use of alternative measures would be inefficient for distant subsidiaries (Hassel 1991). In countries with small cultural distance to headquarters, budgetary control seems effective as common culture motivates subsidiaries to meet budgets. For more distant units, it takes extensive communication and participation in the budget process to align these subsidiaries with corporate goals (Hassel and Cunningham 2004). Training serves as a means to narrow the gap between headquarters and foreign units (Al-Husan and James 2003; Moilanen 2007; Schaaper et al. 2011). Cultural distance is positively related to the delegation of expatriates, whereby the importance of expatriates is higher for younger subsidiaries and diminishes over time as the MNC (Moilanen 2008; Wilkinson et al. 2008). In contrast 
to cultural distance, geographical distance seems to impair only individual control mechanisms, like real-time communication (Sheu et al. 2004) or the willingness of managers to go abroad (Schaaper et al. 2011). Insights on the use of financial performance measures and incentives related to cultural distance date back to the $1990 \mathrm{~s}$ but lack current findings. The majority of studies (13 out of 21) conducted since 2003 explore the introduction of control systems and social control mechanisms to overcome cultural distance between business units. Eleven studies investigate cultural distance for subsidiaries in emerging countries in Asia and Eastern Europe with Western headquarters, another five studies compare Western with East Asian MNCs and six explore cultural distance within Western countries. While quantitative studies (10) focus on impacts on output control like budgeting and reporting or the presence of expatriates, qualitative studies (12) explore a wide range of control mechanisms.

Organizational interdependence within an MNC refers to the dependence of a foreign subsidiary's results on other units within the organization (O'Donnell 2000). Interdependence increases with size and age of subsidiaries (Harzing and Sorge 2003). Highly integrated MNCs apply tight control mechanisms (Andersson and Forsgren 1996; Lin 2014), which is related to higher performance (Lin 2014). Process controls intensify with increasing integration (Chung et al. 2000; Gencturk and Aulakh 1995; Martinez and Jarillo 1991). This effect seems to be even stronger in terms of social control, which includes participation in teams, socialization and informal communication (Martinez and Jarillo 1991). High interdependence between headquarters and subsidiaries is associated with strong relationships between headquarters and subsidiary managers (Chung et al. 2000; O'Donnell 2000) particularly when knowledge exchange between business units is high (Chung et al. 2000). Moreover interdependence is linked with non-monetary incentives (O'Donnell 2000; Roth and O'Donnell 1996) that are either related to the managers' career prospects or the subsidiary's success (O'Donnell 2000). Frow et al. (2005) highlight that interdependencies diminish controllability as managers depend on other units' performances to achieve their budget targets. As a consequence, managers try to master this challenge by communicating informally and cooperating in teams. High interdependence between units draws attention to transfer prices between subsidiaries. Transfer prices that subsidiaries perceive as unfair, may fuel conflicts when local and global goals diverge (Busco et al. 2008). MNCs adapt their PMS to international interdependence by participating subsidiaries in the design of PMS and including non-financial indicators to consider effects that are beyond the control of the respective subsidiary (Dossi and Patelli 2010; Du et al. 2013). In case of subsidiary participation, the emphasis on non-financial indicators increases to allow for broader performance measurement (Dossi and Patelli 2010). The influence of a PMS on subsidiary decisions is higher, if subsidiaries co-designed the PMS and therefore measures are perceived as adequate (Dossi and Patelli 2008). Chung et al. (2000) find that the effects on output control seem to depend on the type of interdependence. As product-related interdependencies increase, marketing and manufacturing measures gain importance, while financial controls do not change. The contribution of capital determines the level of subsidiary control (Chung et al. 2000; Dong et al. 2008; Taylor 1999). Higher capital contribution is related to tighter financial control and 
control by expatriate managers (Chung et al. 2000; Jaussaud and Schaaper 2006) and an emphasis on financial and marketing output control (Chung et al. 2000). Research findings on interdependence are broad, and cover various control mechanisms. MNCs with high interdependence appear to apply relatively tight process control (e.g., Chung et al. 2000; Martinez and Jarillo 1991). Social control mechanisms facilitate coordination between units in those MNCs (e.g., Frow et al. 2005; Martinez and Jarillo 1991). Interdependence has been studied throughout the whole observation period with qualitative as well as quantitative methods. Early studies investigate process and output control on an aggregated level, while later studies, in particular since 2005 focus on specific mechanisms like budgeting and PMS and accompanying formal and informal communication. Controllability issues caused by high interdependencies are reported in two case studies.

Social relationships enable the implementation of control mechanisms; in particular, the success of a group-wide launch of a new PMS depends on social networks that are built on trust (Dossi and Patelli 2008; Masquefa 2008). Networks, that are in some cases supported by expatriates, facilitate a smooth introduction of process control mechanisms (Brenner and Ambos 2013) as these ties help to reduce resistance to new systems and prevent conflicts (Dossi and Patelli 2008; Masquefa 2008). Special importance is attached to the partnering role of management accountants for the launch of such systems (Masquefa 2008; Moilanen 2007, 2008). Findings for this factor are based predominantly on qualitative studies in European subsidiaries and are therefore transferable to a limited extent only.

The strategic importance of a subsidiary affects output control, which is tighter for subsidiaries with higher relevance within the MNC (Chang and Taylor 1999; Moilanen 2007). For more important subsidiaries, non-financial indicators are included in PMS (Dossi and Patelli 2010). Insights on MC related to strategic importance, however, are isolated.

\subsection{Subsidiary characteristics}

A broad range of subsidiary characteristics, as listed in Table 8, influences MC. 29 articles, that predominantly feature quantitative studies, explore factors like size, age or performance.

The size of a subsidiary relates positively to output control (Chang and Taylor 1999; Gencturk and Aulakh 1995). Headquarters rather link PMS with reward mechanisms at large subsidiaries to increase influence on decisions at these units (Dossi and Patelli 2008; Mahlendorf et al. 2012). For larger subsidiaries, non-financial indicators - in particular process indicators - are integrated in PMS to capture different aspects of performance (Dossi and Patelli 2010). Training and other social controls correlate positively with a subsidiary's size (Jaussaud and Schaaper 2006), while the share of expatriates decreases with growing staff numbers (Harzing and Sorge 2003). Also, growing staff numbers raise the influence of headquarters on personnel management (Taylor 1999). In larger subsidiaries the board of directors engage more in coordinating activities to align them with corporate goals (Du et al. 2015). However, Richards (2000) did not find significant effects on overall control. 
Table 8 Subsidiary characteristics

\begin{tabular}{|c|c|c|}
\hline Factor & No. & Sources \\
\hline Size & 10 & $\begin{array}{l}\text { Chang and Taylor (1999), Dossi and Patelli (2008, 2010), Du et al. (2015), } \\
\text { Gencturk and Aulakh (1995), Harzing and Sorge (2003), Jaussaud and } \\
\text { Schaaper (2006), Mahlendorf et al. (2012), Richards (2000) and Taylor } \\
\text { (1999) }\end{array}$ \\
\hline Age & 9 & $\begin{array}{l}\text { Brenner and Ambos (2013), Dossi and Patelli (2008), Harzing (2001), Har- } \\
\text { zing and Sorge (2003), Kranias (2000), Moilanen (2007, 2008), Wilkinson } \\
\text { et al. (2008) and Yu et al. (2006) }\end{array}$ \\
\hline $\begin{array}{l}\text { Form of estab- } \\
\text { lishment }\end{array}$ & 8 & $\begin{array}{l}\text { Al-Husan and James (2003), Andersson and Forsgren (1996), Aulakh } \\
\text { and Gencturk (2000), Du et al. (2015), Harzing (2001), Jaussaud and } \\
\text { Schaaper (2006), Moilanen (2007) and Yu et al. (2006) }\end{array}$ \\
\hline Management & 7 & $\begin{array}{l}\text { Du et al. (2015), Lovett et al. (2009), Lowe et al. (2000), Moilanen (2008), } \\
\text { Mongiello and Harris (2006), Richards (2000) and Roth and O'Donnell } \\
\text { (1996) }\end{array}$ \\
\hline Objectives & 4 & $\begin{array}{l}\text { Cools and Slagmulder (2009), Lovett et al. (2009), Taylor (1999) and Wil- } \\
\text { liams and van Triest (2009) }\end{array}$ \\
\hline $\begin{array}{l}\text { Business func- } \\
\text { tion }\end{array}$ & 4 & $\begin{array}{l}\text { Jaussaud and Schaaper (2006), Lin (2014), Pudelko and Tenzer (2013) and } \\
\text { Yu et al. (2006) }\end{array}$ \\
\hline Performance & 3 & Dossi and Patelli (2010), Lovett et al. (2009) and Richards (2000) \\
\hline
\end{tabular}

References with quantitative research design in bold

This might be due to the research design. Other studies focused on specific mechanisms of control, while Richards (2000) investigated the extent of perceived overall control. Early studies focus on output control and expatriates, since 2008 the impact on PMS has been explored. No results for process controls have been reported.

The age of a subsidiary influences the control that is exerted by the headquarters. As the experience of subsidiaries grows, the autonomy of the local management increases (Kranias 2000; Moilanen 2007; Yu et al. 2006) while process controls decrease (Yu et al. 2006) and means of control adapt to host country requirements (Dossi and Patelli 2008; Kranias 2000). Social control mechanisms like trainings or networks support the introduction of process and output control in early stages by creating trust and building legitimacy (Brenner and Ambos 2013; Moilanen 2007). In particular, the presence of expatriates is important for setting-up new subsidiaries in culturally distant regions and reduces with increasing age (Harzing and Sorge 2003; Moilanen 2008; Wilkinson et al. 2008). The role of expatriates seems to change over time to a more informal control via networks, particularly in relatively independent subsidiaries (Harzing 2001). At mature subsidiaries, management information systems ensure standard reporting lines (Brenner and Ambos 2013; Moilanen 2007). However, the PMS of the headquarters is more likely to compete with a local PMS that is in line with local needs (Dossi and Patelli 2008). Insights on the effects of a subsidiary's age have been reported since the early 2000s with an emphasis on extent and combination of control mechanisms. As the establishment of a subsidiary's control structures and local networks takes time, control mechanisms are adjusted to the development stage with intense monitoring at the beginning and looser process and output control to allow mature subsidiaries higher autonomy and 
localization (e.g., Brenner and Ambos 2013; Yu et al. 2006). Insights from qualitative studies are largely supported by quantitative surveys for emerging as well as industrialized countries. Qualitative studies report on social control mechanisms as trailblazers for other control mechanisms.

The form of establishment describes whether the MNC builds its foreign operations from scratch as a green-field investment, acquires a company, or forms a joint venture together with a foreign partner. At wholly-owned foreign subsidiaries, MNCs apply control by staffing key management positions and expatriates, while training, formal regulations, and knowledge transfer appear common at joint ventures, particularly when the capital share is low (Jaussaud and Schaaper 2006). The influence of headquarters on subsidiary decisions is higher in case of wholly-owned subsidiaries than of joint ventures ( $\mathrm{Yu}$ et al. 2006). In partly-owned subsidiaries, the board of directors is deeply involved in strategy development to safeguard corporate goals (Du et al. 2015). With green-field operations, reporting structures can be implemented from scratch according to their respective requirements (Moilanen 2007), whereas with acquisitions a higher effort is needed to integrate the subsidiary into the MNC (Andersson and Forsgren 1996; Moilanen 2007). In addition, the role of expatriates building formal and informal communication and networks is important to spread corporate values (Al-Husan and James 2003; Harzing 2001). Aulakh and Gencturk (2000) found different effects of control mechanisms on whollyowned subsidiaries and autonomous external distributors: Output controls induce negative effects on perceived compliance and performance of external agents. Social controls, on the other hand, have a positive effect on flexibility and performance of external partners as well as subsidiaries, although stronger in case of the latter. Process controls do not affect the economic performance of both, but lead to perception of higher compliance. Main findings on the form of establishment have been derived from a limited pool of quantitative studies since 2000. From an MC perspective, establishing a wholly-owned foreign subsidiary from scratch seems to facilitate control, as joint venture partners or an acquisitions' history add complexity.

Characteristics of a subsidiary's management like experience or cultural background influence the level of control that is applied by headquarters. Unsurprisingly, MNCs concede more autonomy to experienced managers (Du et al. 2015; Moilanen 2008; Mongiello and Harris 2006). CEOs with longer tenure are controlled less by the subsidiary's board of directors (Du et al. 2015). Managerial commitment seems to facilitate the implementation of corporate culture (Lowe et al. 2000). Incentives of senior managers increase with higher commitment, but corporate performance gains weight with lower commitment (Roth and O'Donnell 1996). The cultural background of managers appears to influence MC. Local managers in emerging countries are rather subject to tighter control than managers of Western countries (Lovett et al. 2009; Richards 2000), although sending expatriates to foreign countries seems to even tighten control (Richards 2000). Findings on this factor have been derived from qualitative as well as from quantitative studies since 2000. A relationship of autonomy level and the manager's experience has been reported from European subsidiaries only.

Besides the overall strategy of the MNC, the objective of a specific subsidiary affects the extent and focus, as well as the mechanisms of control. Subsidiaries serve 
different purposes within an MNC which is reflected in MC. MNCs seem to concede more autonomy to innovative subsidiaries to allow for the use of local resources (Cools and Slagmulder 2009; Williams and van Triest 2009); however, such subsidiaries tend to be subjected to high social control (Lovett et al. 2009). MNCs that aim to enter new markets accept lower levels of subsidiary control in order to gain access to new opportunities (Taylor 1999). Findings on this factor are isolated, which makes it difficult to deduce general statements.

Although control of specific business functions is not the primary focus of this review, some articles contain such findings. Research activity at the subsidiary is related negatively to process control given that these activities are complex and other forms of control might be more suitable (Yu et al. 2006). Manufacturing subsidiaries can enhance performance if tightly controlled, as local responsiveness are not necessarily required (Lin 2014). Transferring expatriates (Pudelko and Tenzer 2013) and knowledge to subsidiaries complements other control mechanisms in production and technology (Jaussaud and Schaaper 2006; Pudelko and Tenzer 2013). In addition, Pudelko and Tenzer (2013) found that control for finance and accounting as well as sales, marketing and human resource management is comprehensive. It seems that functions that are critical to success are controlled more tightly unless flexibility is required.

The performance of a subsidiary is associated particularly with the extent and focus of control. Two studies on US MNCs found, that subsidiaries with relatively poor performance are subject to tighter control (Lovett et al. 2009; Richards 2000) and closer monitoring by expatriate managers (Richards 2000). While for profitable subsidiaries non-financial measures like personnel indicators are included in PMS, for low-performing subsidiaries the control focus lies on financial performance alone (Dossi and Patelli 2010). There are only occasional findings that suggest performance as influencing factor; however, the relevant quantitative studies provide consistent results — at least for Western MNCs.

\subsection{Environment and local networks of subsidiaries}

The environment of subsidiaries shapes the control system of foreign subsidiaries. 43 studies analyze various environmental factors as presented in Table 9.

The national culture and business traditions of the host country affect MC particularly in terms of budgeting and budget-related incentives (Hoffjan et al. 2012; Van der Stede 2003). Subsidiaries in countries with high power distance and an uncertainty-avoiding culture implement comprehensive budgeting processes and tolerate more interference from headquarters (Van der Stede 2003). Budgeting and planning are common practices in Anglo-Saxon and German-speaking countries with high employee participation, while planning is considered less important in Russia (Keplinger et al. 2012; Moilanen 2007). Due to its perceived inflexibility, budgeting is also of lower relevance in France and financially oriented incentive systems may be less effective there (Hoffjan et al. 2012). Similarly, in China, budgeting plays a minor role and incentives are only weakly linked to budgets (O'Connor et al. 2011). Subsidiaries in countries with high individualism index are prone to 
Table 9 Environment and local networks of subsidiary

\begin{tabular}{|c|c|c|}
\hline Factor & No. & Sources \\
\hline Culture, traditions & 13 & $\begin{array}{l}\text { Avison and Malaurent (2007), Beard and Al-Rai (1999), Carr and Tom- } \\
\text { kins (1996), Chow et al. (1999), Dossi and Patelli (2008), Hoffjan et al. } \\
\text { (2012), Keplinger et al. (2012), Lovett et al. (2009), Moilanen (2007), } \\
\text { O'Connor et al. (2011), Sheu et al. (2004), Van der Stede (2003) and } \\
\text { Williams and van Triest (2009) }\end{array}$ \\
\hline $\begin{array}{l}\text { Environmental } \\
\text { uncertainty }\end{array}$ & 13 & $\begin{array}{l}\text { Abdallah and Alnamri (2015), Borkowski (1999), Chang et al. (2009), } \\
\text { Dossi and Patelli (2010), Gencturk and Aulakh (1995), Giacobbe } \\
\text { et al. (2016), Hassel (1991), Hassel and Cunningham (1996), Kihn } \\
\text { (2007, 2008), Mahlendorf et al. (2012), Moilanen (2007) and Mong- } \\
\text { iello and Harris (2006) }\end{array}$ \\
\hline Market requirements & 12 & $\begin{array}{l}\text { Al Chen et al. (1997), Al-Husan and James (2003), Busco et al. (2008), } \\
\text { Carr and Tomkins (1996), Dossi and Patelli (2008), Gencturk and } \\
\text { Aulakh (1995), Hoque and Chia (2012), Kihn (2008), Lowe et al. } \\
\text { (2000), Lin (2014), Mongiello and Harris (2006) and O'Connor et al. } \\
\text { (2011) }\end{array}$ \\
\hline $\begin{array}{l}\text { Legal and political } \\
\text { conditions }\end{array}$ & 10 & $\begin{array}{l}\text { Avison and Malaurent (2007), Beard and Al-Rai (1999), Fernandez- } \\
\text { Revuelta Perez and Robson (1999), Lowe et al. (2000), Masquefa } \\
\text { (2008), Moilanen }(2007,2008), \text { Schaaper et al. (2011), Sheu et al. } \\
\text { (2004) and Taylor (1999) }\end{array}$ \\
\hline Local embeddedness & 7 & $\begin{array}{l}\text { Andersson and Forsgren (1996), Harzing (2001), Lin (2014), Mahlen- } \\
\text { dorf et al. (2012), Martinez and Jarillo (1991), Schaeffer et al. (2014) } \\
\text { and Yu et al. (2006) }\end{array}$ \\
\hline $\begin{array}{l}\text { Labor market and } \\
\text { education }\end{array}$ & 5 & $\begin{array}{l}\text { Carr and Tomkins (1996), Chang et al. (2009), Lowe et al. (2000), Moil- } \\
\text { anen (2007) and Sheu et al. (2004) }\end{array}$ \\
\hline Economy & 5 & $\begin{array}{l}\text { Lowe et al. (2000), Moilanen (2007, 2008), Schaaper et al. (2011) and Yu } \\
\text { et al. (2006) }\end{array}$ \\
\hline Language & 3 & $\begin{array}{l}\text { Avison and Malaurent (2007), Björkman and Piekkari (2009) and Sheu } \\
\text { et al. (2004) }\end{array}$ \\
\hline
\end{tabular}

References with quantitative research design in bold

implement a local PMS that competes with the headquarters' PMS for influencing subsidiary decisions (Dossi and Patelli 2008). In some emerging countries, Western MC tools like BSC, despite being implemented for reporting matters, are not used for decision making by the subsidiary management (Moilanen 2007; O'Connor et al. 2011). Similarly, management information systems that are inconsistent with local business traditions lack acceptance in the host country (Avison and Malaurent 2007; Sheu et al. 2004). Managers in countries with uncertainty-avoiding culture prefer clear regulations and accept the centralization of decision making (Lovett et al. 2009; Williams and van Triest 2009). In Middle Eastern cultures social ties and trust outweigh written contracts in importance (Beard and Al-Rai 1999). Similarly, in Eastern Europe and Russia personal relationships are valued and personal communication supports formal reporting (Keplinger et al. 2012; Moilanen 2007). For the implementation of MC, a basic understanding of a subsidiary's national culture is key. While Western cultures show a low tendency to avoid conflicts and generally accept criticism, Russian employees are more conflict averse (Keplinger et al. 2012) and for Chinese employees public criticism even means to lose their face 
(Avison and Malaurent 2007). These facts need to be taken into account when conflicts arise. Observations on culture and tradition derive from qualitative and quantitative studies including emerging countries like Mexico, China and Russia as well as Western countries. Insights on the importance of budgeting in specific countries (Hoffjan et al. 2012; Keplinger et al. 2012) as well as on communication and conflict aversion originate from qualitative studies (Avison and Malaurent 2007; Keplinger et al. 2012). Recent studies still report on the effects of host country culture and traditions, so this issue seems not to have disappeared with time. Main results relate to output control and the introduction of management information systems. Some control mechanisms appear to lack legitimacy in host countries and, therefore, may not lead to the desired results. Communication and social relationships between headquarters and subsidiaries could partly compensate for this shortfall.

With growing environmental uncertainty the emphasis on financial measures (Giacobbe et al. 2016; Hassel 1991; Kihn 2007), as well as the importance of nonfinancial indicators, increases (Abdallah and Alnamri 2015; Dossi and Patelli 2010; Kihn 2007). The dynamic environment of a subsidiary requires adapting non-financial controls (Borkowski 1999; Kihn 2007) and asks for intensified communication between subsidiary and headquarters to ensure stable performance at the subsidiary (Hassel and Cunningham 1996; Moilanen 2007). Increasing complexity of PMS due to high dynamism lowers the acceptance of such measures (Hassel 1991; Mahlendorf et al. 2012) and diminishes their influence on subsidiary decisions (Mahlendorf et al. 2012). In a dynamic environment, output control is more difficult to apply as precise goals are hard to define (Gencturk and Aulakh 1995; Hassel and Cunningham 1996; Mongiello and Harris 2006). MNCs complement output control with process controls in response to environmental uncertainty (Brenner and Ambos 2013; Gencturk and Aulakh 1995; Kihn 2008). Currency fluctuations and inflation seem not to affect MNC controls on a large scale, as they are only mentioned in one case study (Moilanen 2007). Findings on environmental uncertainty are reported predominantly by quantitative studies over the whole investigation period. Although predictability of financial goals is limited, these measures are widely used to control subsidiaries in dynamic environments, however, frequently complemented with nonfinancial measures, process and social control. These findings appear to be consistent and stable over time.

Competitive markets require sophisticated MC mechanisms. In such environments, monitoring activities seem more effective than controlling output to achieve higher performance (Gencturk and Aulakh 1995). High competition increases the importance of MC, as well as the pressure on cost efficiency (Al Chen et al. 1997; Al-Husan and James 2003; O'Connor et al. 2011). At subsidiaries in competitive markets, PMS has higher influence on subsidiary decisions (Dossi and Patelli 2008) and diverse measurement perspectives including non-financial indicators become increasingly important (Dossi and Patelli 2008; Hoque and Chia 2012; Kihn 2008). Markets that necessitate high product diversity challenge production as well as supervisory systems and increase the complexity of MC (Lowe et al. 2000). Adapting products and services to local market requirements demands a certain autonomy and seems incompatible with tight control and culture transfer from headquarters (Lin 2014). Requirements of local markets may contradict global strategy and 
profitability necessities, thus causing goal conflicts (Busco et al. 2008). This affects the PMS of subsidiaries and either leads to local adaptation of global MC systems e.g., by including indicators that match local requirements (Dossi and Patelli 2008; Mongiello and Harris 2006) or to subsidiaries that manage their local business while relying on their own measures and systems, which maintains goal conflicts (Busco et al. 2008; Dossi and Patelli 2008) and lowers the influence of headquarters on subsidiaries (Dossi and Patelli 2008). Since 2006 the influence of market requirements on PMS has been a major research interest, indicating that PMS needs to serve both, headquarters and subsidiary needs to be of use for decision making. Findings from qualitative studies match those from quantitative studies.

Political and legal conditions influence MCSs. Entering transitional markets such as China may come along with ownership and control restrictions (Taylor 1999) although a recent study claims that these restrictions have diminished at least in China (Schaaper et al. 2011). Moreover, applicable laws may change unexpectedly in emerging countries (Beard and Al-Rai 1999; Moilanen 2008). Political influence is not a phenomenon limited to emerging countries, however; a case in Europe illustrates that political influence in form of subsidies provided by the state and the EU for an otherwise unprofitable subsidiary led to unrealistic budgeting processes (Fernandez-Revuelta Perez and Robson 1999). Strong influence of trade unions in the UK demands that MC needs to comply with agreed procedures (Lowe et al. 2000). In addition, the deregulation of industries creates the demand to implement PMS in previously protected sectors (Masquefa 2008). Diverging legal requirements may complicate the launch of a global management information system as it has to meet the legal regulations of all countries involved, which is challenging even within Europe (Moilanen 2007, 2008; Sheu et al. 2004). Different legal backgrounds may lead to localized solutions (Avison and Malaurent 2007; Sheu et al. 2004) and, in the worst case, to parallel systems with double entry procedures (Avison and Malaurent 2007). Contributions on legal and political frameworks derive from case studies, which suggest that unstable legal conditions and the diverging legal frameworks of the involved countries seem to complicate the introduction of MCSs.

Local embeddedness is characterized by the interactions of a subsidiary with its local business network and environment. High local embeddedness diminishes the control of headquarters as perceived by the subsidiary and may impede the influence of headquarters (Andersson and Forsgren 1996). However, locally embedded firms operate largely autonomously and seem not to require much coordination (Lin 2014; Martinez and Jarillo 1991). However, expatriates appear to be an important coordination mechanism in locally embedded subsidiaries (Harzing 2001). When a subsidiary establishes links with local firms or local governments in emerging countries, headquarters reduces the extent of close monitoring and influence on subsidiary decisions (Yu et al. 2006). PMS strongly influence subsidiary decisions when their local embeddedness is high (Mahlendorf et al. 2012). However, the interactive use of PMS at locally well-connected subsidiaries weakens performance, as it seems to tie resources in internal discussions that could be used more effectively in local relationships (Schaeffer et al. 2014). Observations on local interactions of foreign subsidiaries have been reported in quantitative papers over the whole investigation 
period. To sum up, locally embedded subsidiaries require a certain autonomy to react to the local environment.

Labor markets, in particular, a country's availability of high-skilled staff and wage levels affect MC. High wages in European countries require strategic investments to secure competitive advantages through innovation (Carr and Tomkins 1996) or encourage foreign MNCs to search for alternatives in form of short-term contracts, that require tight control (Chang et al. 2009). A well-trained workforce facilitates the implementation of supervisory systems (Lowe et al. 2000), the launch of management information systems (Sheu et al. 2004) and simplifies the alignment of a foreign subsidiary with Western corporate culture (Moilanen 2007). A lack of skilled workforce delays training programs and may result in having to outsource tasks (Sheu et al. 2004). Findings on this factor are based on qualitative studies, which suggest that the availability of well-educated staff simplifies the control of foreign subsidiaries.

Economic conditions in form of crisis situations or the economic stage of a country shape MC. After the economic crisis in 2009, Western MNCs centralized MC and expatriates at foreign subsidiaries were widely replaced by local managers and additional trainings (Schaaper et al. 2011). In emerging economies reporting standards may differ from requirements in industrial countries. MNCs need to ensure a certain standard for reliable reporting and therefore put some effort into informal relationships and operational control through supervision (Moilanen 2007, 2008). However, commitment of managers may be high as a job at an MNC appears to be desirable in emerging countries (Lowe et al. 2000). Economic environment is investigated in the context of legal and political conditions as well as of uncertainty and has been explored by predominantly qualitative studies with isolated results.

Subsidiaries with low command of the language spoken at headquarters face more centralized and process control than those at countries with higher language competence (Björkman and Piekkari 2009). Particularly the launch of management information systems is complicated if language command is weak at subsidiaries, which hinders communication and comprehending instructions (Avison and Malaurent 2007). Using information systems in the group language, not in the local language increases employee resistance to the new system and requires additional training and other local resources (Avison and Malaurent 2007; Sheu et al. 2004). Findings on this factor are scarce with limited generalizability.

\section{Discussion}

\subsection{Decentralized versus multinational organizations}

Large decentralized firms and multinational corporations have certain elements in common. Decentralized firms tend to delegate significant decision-making authority to subunit managers, as usually local or specialized knowledge is available on a business unit level, which allows adequate and timely decisions (Blocher et al. 2010; Horngren et al. 2012). These benefits, however, may be outweighed by adverse effects. Decentralization may lead to suboptimal decisions when the benefit of one 
subunit goes at the expense of another unit due to the management focusing on subunit results rather than corporate ones (Anthony et al. 2014; Horngren et al. 2012). $\mathrm{MC}$ in decentralized firms relies strongly on formal information through integrated reports or budgeting processes (Chenhall 2003). These attributes are confirmed by articles included in our review. We found, that decentralized firms if necessary concede decision rights to subsidiaries to adapt to market developments (e.g., Mongiello and Harris 2006; Williams and van Triest 2009). Moreover, we identified negative effects of centralization hindering flexibility in local subsidiaries (e.g., Cools et al. 2008; Richards and Hu 2003) or resulting in cost increases caused by the implementation of control mechanisms as imposed by headquarters (e.g., Avison and Malaurent 2007; Cools and Slagmulder 2009). Negative effects of decentralization in terms of limited controllability of conditions are reported in case studies (e.g., Busco et al. 2008; Frow et al. 2005). A strong focus on formalized reporting and procedures or complex budgeting processes, is suggested by various studies (e.g., Chung et al. 2006; Jaussaud and Schaaper 2006; Van der Stede 2003). Additionally, we identified means to align subsidiaries with corporate goals like PMS and incentives (e.g., Mahlendorf et al. 2012; Roth and O’Donnell 1996).

MNCs are often decentralized as the feasibility of headquarters control for geographically disperse units is low (Horngren et al. 2012). In addition to challenges in decentralized domestic companies, local business environments and cultural differences add complexity in MNCs (Horngren et al. 2012; Merchant and Van der Stede 2017). Our findings confirm that culture and business traditions in the host country may complicate the transfer of control mechanisms due to lacking acceptance (e.g., Avison and Malaurent 2007; Hoffjan et al. 2012). However, cultural dimensions are not the only determinant for the design of MCS. Market requirements and legal as well as political conditions may differ significantly from the home market and some control mechanisms seem ineffective when improperly adapted to the locally prevailing conditions (e.g., Beard and Al-Rai 1999; Lowe et al. 2000). In addition, we find that MNC characteristics such as size, degree of internationalization and corporate culture (e.g., Epstein and Roy 2007; Kihn 2010), and particularly the home country of the MNC (e.g., Chow et al. 1999; O'Connor et al. 2011) affect MC. Moreover, the interdependence within the MNC as well as subsidiary characteristics shape the applied control mechanisms (e.g., Dossi and Patelli 2010; Harzing and Sorge 2003). The implementation of an adequate PMS as well as information and communication technologies are suggested to facilitate control in MNCs (Horngren et al. 2012). Our review further suggests that internationalization activities correlate with an emphasis on output control (e.g., Gencturk and Aulakh 1995; Kihn 2010) with attention to non-financial goals to respond to the challenge of various environmental factors in host countries (e.g., Dossi and Patelli 2010; Du et al. 2013). Moreover, a broad range of social control mechanisms as training, meetings or informal communication complement MCS (e.g., Brenner and Ambos 2013; Martinez and Jarillo 1991), as indicated only marginally in textbooks on MC. Contrary to what MC textbooks say, currency exchange rates (Horngren et al. 2012; Merchant and Van der Stede 2017) seem to be a non-issue for MC in today's MNCs, as they go largely unmentioned. 
Decentralized companies exchange products and/or services between subunits. Transfer prices for these exchanges aim to coordinate and evaluate the performance of the subunits. In domestic trade, economic considerations largely determine transfer prices (Blocher et al. 2010; Horngren et al. 2012). In international exchanges, an integration of managerial and tax objectives is suggested to yield optimum results (Baldenius et al. 2004). In several case studies on this subject, tax compliance is described as the overwhelming determinant for the transfer price policy of MNCs with far-reaching effects on PMS and subsidiary flexibility (Cools et al. 2008; Cools and Slagmulder 2009; Plesner Rossing 2013). This confirms the statements of Blocher et al. (2010) and Horngren et al. (2012) on multinational exchanges. Only one case reports standardized transfer prices according to PMS requirements (Busco et al. 2008).

\subsection{Developed versus emerging countries}

MNCs that originate from emerging countries are underrepresented in our review. Most articles deal with MNCs headquartered in industrialized countries. Only four studies focus on MNCs from Taiwan or China, other regions are totally neglected. 18 articles investigate subsidiaries in emerging countries, predominantly in Asia, Eastern Europe or Mexico. Although these subsidiaries are located in different geographical and cultural areas, they have certain elements in common. While in developed countries legal and economic stability is widespread, emerging countries show relatively volatile legal and economic conditions, which poses a challenge for MC (e.g., Beard and Al-Rai 1999; Moilanen 2008). Education differs between countries and affects the availability of well-trained staff with sufficient language command (Moilanen 2007; Sheu et al. 2004). Depending on business traditions of the respective country, profit-orientation may be less pronounced and business practices may vary widely from those of the Western world (e.g., Al-Husan and James 2003; O'Connor et al. 2011). To implement a corporate culture that goes in line with Western business practices, MNCs bank on socialization through intense communication, meetings, trainings, expatriate managers and process control with clearly defined standards and procedures as well as the integration of management information systems (e.g., Al-Husan and James 2003; Moilanen 2007).

\subsection{Findings for theoretical frameworks}

To investigate $\mathrm{MC}$ at MNCs, a broad range of theories was applied as presented in Table 10. 16 articles apply more than one theory. Nine case studies are exploratory using a theory-building approach and therefore do not apply a specific theoretical frame. Three descriptive studies with quantitative research design do not disclose a specific theory as framework, but define the investigated control mechanisms according to renowned literature. In the following section we discuss how our findings relate to the most frequently used theoretical frames, namely Hofstede's cultural dimensions, contingency and agency theory. 
Table 10 Overview of influencing factors by theory (multiple assignment of articles)

\begin{tabular}{|c|c|c|c|c|c|c|}
\hline Theory & Total articles & $\begin{array}{l}\text { MNC } \\
\text { character- } \\
\text { istics }\end{array}$ & $\begin{array}{l}\text { MNC } \\
\text { environ- } \\
\text { ment }\end{array}$ & $\begin{array}{l}\text { Relation to } \\
\text { subsidiary }\end{array}$ & $\begin{array}{l}\text { Subsidiary } \\
\text { character- } \\
\text { istics }\end{array}$ & $\begin{array}{l}\text { Subsidiary } \\
\text { environment }\end{array}$ \\
\hline Culture Dimensions & 18 & 6 & 5 & 11 & 6 & 11 \\
\hline Contingency & 17 & 10 & 4 & 10 & 6 & 10 \\
\hline Agency & 13 & 5 & 4 & 7 & 11 & 4 \\
\hline Other theories & 25 & 15 & 10 & 13 & 6 & 14 \\
\hline $\begin{array}{l}\text { Exploratory/descrip- } \\
\text { tive }\end{array}$ & 12 & 6 & 6 & 4 & 6 & 6 \\
\hline
\end{tabular}

Hofstede's (2001) cultural dimensions were applied 18 times to analyze differences between subsidiaries' host countries as well as cultural distance between the country of origin and the host country. Hofstede (2001) defines culture along five dimensions, namely individualism versus collectivism, power distance, uncertainty avoidance, masculinity versus femininity and long term versus short term orientation. In our review we find support for cultural differences between countries. In countries with short-term orientation like UK and US, short-term measures are emphasized, while in Germany and Japan, which are attributed with long-term orientation, longer time horizons prevail for PMS (e.g., Borkowski 1999; Coates et al. 1995). However, in case of the former, the cultural dimensions could tie to the capital market orientation in Anglo-Saxon countries, which also fosters short-term horizons. For uncertainty avoidance some unexpected results were identified: Russian and French cultures show high scores on uncertainty avoidance, planning, however, appears less relevant (e.g., Hoffjan et al. 2012; Keplinger et al. 2012). In the case of Russia, the volatile environment, which limits the validity of plans, could explain this contradictory finding (Moilanen 2007). Although power distance is relatively low and the individual index is high in the US, MNCs show strong centralization tendencies (e.g., Chow et al. 1999; Williams and van Triest 2009) contrary to theoretical assumptions. In addition, these attributes are suggested to favor the inclusion of non-financial indicators which is also not confirmed for the US (e.g., Borkowski 1999; Coates et al. 1995). While overall calculations of distance based on cultural dimensions show certain validity, individual attributes of a national culture appear less significant, given the large variations in MNCs related to corporate, industry or country characteristics, besides culture. Hofstede's cultural dimensions are often used to define cultural distance in combination with other theories, e.g., contingency theory or agency theory.

Contingency theory was applied 17 times as theoretical lens identifying a large amount of influencing factors on the design of MC. Findings are based predominantly on Western MNCs located in Europe or the US with subsidiaries in developed countries. Contingency theory examines the effects of MNC characteristics or the subsidiary's environment in terms of uncertainty or market requirements as well as subsidiary characteristics. Particularly the degree of internationalization and interdependence between business units and their effects on PMS (e.g., Kihn 2008; 
Mongiello and Harris 2006) and the use of non-financial indicators have been analyzed (e.g., Chung et al. 2000; Kihn 2007). Both, a high degree of internationalization as well as environmental uncertainty encourage the focus on output control complemented by non-financial performance measures and process controls. Culture is an essential determinant; however, characteristics of MNCs like degree of internationalization, strategy or industry as well as external context factors such as environmental uncertainty or capital market orientation might overlap with cultural dimensions (e.g., Harzing and Sorge 2003; Van der Stede 2003). For coordinating global activity, MNCs aim at transferring their MCS to different countries. The PMS is adapted according to uncertainty and market requirements by including broader measurement ranges (e.g., Dossi and Patelli 2010; Kihn 2007). Adaptation to host country specifications requires a certain autonomy with decision rights for local management (e.g., Mongiello and Harris 2006; Yu et al. 2006). MNCs rely on different control mechanisms like training, expatriates or process control to transfer their corporate culture and MCS to foreign subsidiaries and thereby narrowing effects of host country characteristics (e.g., Al-Husan and James 2003; Lin 2014).

Agency theory (Jensen and Meckling 1976) has been applied 13 times since 1996 to investigate headquarters control mechanisms in subsidiaries in developed as well as emerging countries. Besides output control in form of PMS and incentives, foreign subsidiaries (agents) are coordinated by defining decision rights and other process controls as well as communication and positioning expatriate managers to reduce information asymmetry between headquarters and subsidiaries (e.g., Brenner and Ambos 2013; Chang and Taylor 1999). Headquarters nationality, characteristics of subsidiaries (size, age, form of establishment) as well as interdependence between business units are determining factors for MCS within agency frameworks (e.g., Dossi and Patelli 2010; Yu et al. 2006). Interdependence between business units is related to intense communication and incentives as well as participation of subsidiaries in the design of PMS (e.g., Dossi and Patelli 2010; Du et al. 2013; O'Donnell 2000). The environment of the subsidiary seems less relevant for agency frameworks.

Each theoretical frame deals with various sets of control mechanisms as well as influencing factors. Nevertheless, certain tendencies are visible. Hofstede's cultural dimensions focus as is to be expected on the culture of the host country and cultural distance as well as on centralization and budgeting but provide no explanation for the presence of expatriate managers that are addressed by agency theory as well as contingency theory. Decentralization by conceding decision rights to subsidiaries is addressed particularly by agency theory. Culture, however, is not an issue in these articles. Contributions applying contingency theory include a broad range of context factors, with culture just being one among many others.

\section{Conclusion}

The control of foreign subsidiaries is crucial for MNCs. The high number of studies on MC in MNCs indicates that this subject represents a research focus. The main contribution of our paper is to provide an overview of the state of research on MC 
at MNCs over the past 25 years. We have examined a broad spectrum of control mechanisms to provide a common knowledge base for future research, depicting and categorizing numerous influencing factors, their interrelations and effects on several control mechanisms. This research contribution discusses conflicting findings and limitations of certain mechanisms and presents research designs, applied theoretical frames and a summary of the development of control mechanisms as well as of the examined influencing factors over time. There is consensus that output controls particularly in form of financial measures are prevalent and widely accepted. Nonfinancial measures complement financial output controls with regard to complex environments. Process controls ensure that employees at subsidiaries comply with guidelines and act in line with the MNC's goals. Social controls are the trailblazer for other mechanisms of control, particularly in emerging countries, where certain standards need to be established. MNCs apply combined control mechanisms depending on various influencing factors, such as the company environment that affects the MCS (Granlund and Lukka 1998), as well as internal factors like size or strategy (Otley 2016). Some of these, such as corporate strategy, are associated with headquarters; others are attributed to the subsidiary or to the relationship between headquarters and subsidiaries. Most studies investigate more than one influencing factor and identify interactions between these factors. Hence it is safe to say that a combination of factors shape MC at MNCs.

The findings of this paper are of high practical relevance for MNCs. Output controls, especially financial figures, are widely understood and accepted across countries and sectors, which enables benchmarking. Non-financial measures allow adjustment to local requirements and increase the significance of PMS under environmental uncertainty. A broad measurement focus, comprising financial and non-financial indicators can prevent a loss of control over a subsidiary. Nevertheless, PMS that are too complex lose influence due to their incomprehensibility. MC should be adapted to the environment of a subsidiary; especially market requirements, culture, legal frameworks, and languages should be taken into account when implementing MCS. Otherwise, MNCs risk that control mechanisms are ineffective or even cause additional costs. Social controls tend to be neglected, although they smooth the way for process and output controls. Training serves to transfer both knowledge and corporate culture to subsidiaries and ensures that MCSs are, on the one hand, applied correctly and, on the other hand, accepted by subsidiaries-both requirements for effective control. Frequent communication between subsidiaries helps to develop social relationships, which support introducing $\mathrm{MC}$ and resolving conflict situations. Expatriates provide control over subsidiaries, which is particularly important when setting-up new subsidiaries if expatriates are familiar with host country conditions. Process controls are useful mechanisms to control the behavior of employees and align it with company objectives. However, the extensive use of such controls limits flexibility and adaptions to local requirements. Culture is a critical factor for the effective control of subsidiaries. The nationality of the headquarters shapes the control exerted over subsidiaries. Managers at headquarters should realize that these control mechanisms might not be fully understood or accepted in other countries and their respective cultural backgrounds or business traditions. 
Our review also provides recommendations for management accountants. Social relationships are important for implementing MCSs and enhancing the reliability of reporting. Management accountants should build and foster social ties with other departments and subsidiaries. A basic understanding of the culture, language, and other characteristics of the subsidiary's host country is important to be able to implement and coordinate MCSs at foreign subsidiaries. The significance of nonfinancial measures increases with uncertainty and cultural, as well as geographical distance. Management accountants should familiarize themselves with these measures and implement them in PMS and reporting where appropriate.

Despite the existence of a comprehensive research body on $\mathrm{MC}$ at $\mathrm{MNC}$, our paper reveals research gaps and identifies interesting avenues for future research. Research on social control is relatively fragmentary and in the US underrepresented. Expatriate managers are widespread means of control; little is so far known about adequate preconditions for their effective control. The role of social relationships and shared values as fundamental factors for successful implementation of MC partly remains vague. The introduction of management information systems has been investigated mainly in case studies covering European MNCs. Quantitative research designs and findings on other regions could shed different light on this issue.

Although we found numerous influencing factors, there still remain unexplored areas for future research. The majority of extent studies examines manufacturing firms or cross-sectional samples without discussing the differences between sectors; the retail and services sectors remain underrepresented. A comparison of various sectors could identify and discuss diverging practices across sectors. Control of specific business functions like marketing or $\mathrm{R} \& \mathrm{D}$ were not a focus of our review, MC related to these functions as well as the purpose of a subsidiary could become subject to further research. Only few papers investigate the form of subsidiary establishment. Further research could examine MC differences for various forms of establishment including greenfield investments, acquisitions, and joint ventures. Some studies imply that the ownership structure, whether a state-owned or founder-owned company, influences MC. Particularly family ownership impacts international activities of companies (Mitter et al. 2014). Evidence on ownership types, e.g., founder, family or the public is lacking. Moreover findings on small MNCs are currently scarce. The environment of headquarters also shapes its MCS, with nationality of the headquarters being the only factor, which has been investigated comprehensively so far. In the reviewed studies, the vast majority of MNCs is headquartered in industrialized countries. Moreover, there is only scarce evidence on subsidiaries in emerging countries outside China—no study from regions like India, South America or Africa was available. Results relating to capital market orientation are mainly from the US, with occasional results from Europe and missing insights on other regions. Moreover, relationships and interactions between country characteristics like culture or capital market orientation remain unclear, for example related to the short-term orientation of MNCs. Following the successful implementation of the internet around the world at the end of the 1990s, technological innovations related to $\mathrm{MC}$ were investigated in some case studies. Cloud computing could initiate a similar wave of innovations, which might be reflected in MCS. Other factors might exist 
in the environment of an MNC that influence MC: Some are suggested by case studies or qualitative interviews with small sample sizes, for example, effects of strategy implementation and limited controllability of environmental conditions as well as the legitimacy of control mechanisms in different regions. The same applies also to technology, capital market orientation as well as legal, political and economic conditions. These factors could be examined by quantitative research designs to confirm their validity.

We identified contradictory findings which could be subject to further research: The usefulness of incentives based on PMS is unclear and the effects of internationalization on process controls as well as the relationship of shared values and decentralization remain so far unsolved. Moreover, it appears that the explanatory power of cultural dimensions for control mechanisms in MNCs lacks clarity. While cultural distance was investigated mainly under the theoretical lens of Hofstede's cultural dimensions, other cultural studies (e.g., Trompenaars and Hampden-Turner 2012) could enhance the understanding of cultural effects. Contributions comparing cultural differences within Europe date back to the early 2000s. Developments like the European Single Market encourages harmonization of legal and economic conditions and could support a more converging business culture within Europe, which represents an interesting avenue for further research. Many factors shape the environment of foreign subsidiaries. Qualitative case studies suggest effects of education and language on MCS. These factors could be investigated by broad-based quantitative research designs. Moreover, compliance with legal requirements is essential for MNCs. So far, this factor has been investigated solely for tax compliance. Legal compliance issues like the Sarbanes-Oxley Act in the US, other corporate governance standards or corporate codes of conduct and fraud prevention could be investigated related to MC. As reported in case studies, tax regulations shape transfer prices, thereby replacing managerial requirements. Influencing factors for determining transfer prices in MNCs also represent an interesting research field.

We have observed a shift in the focus of articles following the financial crisis since 2007. Although economic crises are considered to influence MCSs (Asel et al. 2011), only one article examines the effects of an economic crisis on MC of MNCs. This calls for further, longitudinal, research on this topic. Recent protectionist tendencies indicate increasing skepticism towards globalization and MNCs. This could lead to trade restrictions in some countries and, in turn, foreign subsidiaries could become even more relevant. In addition, the pressure for the legitimacy of a firm and for the MC it applies could increase. MC of MNCs is a significant issue for management and accounting education. It could be interesting to systematically investigate the dissemination of knowledge in relevant textbooks, similarly to the analysis of strategic management accounting literature conducted by Hoffjan and Wömpener (2006).

As every literature review, this paper has limitations. Articles were searched in seven scientific databases with thoroughly selected keywords, complemented by a search for core contributions referenced in the identified articles. Nevertheless, the search may not have captured all articles that address the subject of this review. The focus of this review is on scientific journals and excludes monographs, conference papers and journals for practitioners. Articles in languages other than English were 
ignored. The papers have been analyzed according to replicable criteria using standardized review protocols. Nevertheless, the interpretation of results in this review are contingent on the authors, with the limitation that other researchers might have clustered factors differently.

Acknowledgements Open access funding provided by FH Salzburg - University of Applied Sciences. We thank the participants of the 40th European Accounting Association Annual Congress 2017 for helpful comments on an earlier version of this paper. We thank Ingrid Hovdar-Stojakovic for her support in this research project.

\section{Compliance with ethical standards}

Conflict of interest The authors declare that they have no conflict of interest.

Open Access This article is distributed under the terms of the Creative Commons Attribution 4.0 International License (http://creativecommons.org/licenses/by/4.0/), which permits unrestricted use, distribution, and reproduction in any medium, provided you give appropriate credit to the original author(s) and the source, provide a link to the Creative Commons license, and indicate if changes were made.

\section{Appendix: Research design of included articles}

\begin{tabular}{|c|c|c|c|c|c|c|c|}
\hline \multirow[t]{2}{*}{ Author/year } & \multicolumn{2}{|c|}{ Quantitative } & \multicolumn{2}{|l|}{ Qualitative } & \multirow{2}{*}{$\begin{array}{l}\text { Country of } \\
\text { headquarters }\end{array}$} & \multirow{2}{*}{$\begin{array}{l}\text { Country of } \\
\text { subsidiary }\end{array}$} & \multirow[t]{2}{*}{ Sector } \\
\hline & Survey & Archive & Interview & Case & & & \\
\hline $\begin{array}{l}\text { Abdallah and Alnamri } \\
\text { (2015) }\end{array}$ & $\checkmark$ & & & & N.D. & SA & M \\
\hline Al Chen et al. (1997) & $\checkmark$ & & & & JP & US & $\mathrm{M}$ \\
\hline $\begin{array}{l}\text { Al-Husan and James } \\
\text { (2003) }\end{array}$ & & & & $\checkmark$ & FR & $\mathrm{JO}$ & SM \\
\hline $\begin{array}{l}\text { Andersson and } \\
\text { Forsgren (1996) }\end{array}$ & $\checkmark$ & & & & SE & N.D. & Cross \\
\hline $\begin{array}{l}\text { Aulakh and Gencturk } \\
(2000)\end{array}$ & $\checkmark$ & & & & US & N.D. & $\mathrm{M}$ \\
\hline $\begin{array}{l}\text { Avison and Malaurent } \\
\text { (2007) }\end{array}$ & & & & $\checkmark$ & FR & $\mathrm{CN}$ & M \\
\hline $\begin{array}{l}\text { Beard and Al-Rai } \\
\text { (1999) }\end{array}$ & & & $\checkmark$ & & US & $\mathrm{JO}$ & Cross \\
\hline $\begin{array}{l}\text { Björkman and Piekkari } \\
\text { (2009) }\end{array}$ & $\checkmark$ & & & & UK US Europe & $\mathrm{CN}$ FI & Cross \\
\hline Borkowski (1999) & & $\checkmark$ & & & $\begin{array}{l}\text { CA DE JP UK } \\
\text { US }\end{array}$ & US & Cross \\
\hline $\begin{array}{l}\text { Brenner and Ambos } \\
\text { (2013) }\end{array}$ & & & $\checkmark$ & $\checkmark$ & Europe US JP & Europe & Cross \\
\hline Busco et al. (2008) & & & & $\checkmark$ & $\mathrm{CH}$ & 130 countries & $\mathrm{M}$ \\
\hline $\begin{array}{l}\text { Carr and Tomkins } \\
\text { (1996) }\end{array}$ & & & & $\checkmark$ & DE UK & DE UK US & M \\
\hline Chang et al. (2009) & $\checkmark$ & & & & TW & UK & $\mathrm{M}$ \\
\hline
\end{tabular}




\section{Author/year \\ Chang and Taylor (1999)}

Country of headquarters
Country of subsidiary

Sector

Survey Archive Interview Case

Chow et al. (1999)

Chung et al. (2000)

Chung et al. (2006)

Coates et al. (1992)

Coates et al. (1995)

Cools and Slagmulder (2009)

Cools et al. (2008)

Cooper and Ezzamel (2013)

Crespo et al. (2014)

Dong et al. (2008)

Dossi and Patelli (2008)

Dossi and Patelli (2010)

Du et al. (2013)

Du et al. (2015)

Epstein and Roy (2007)

Fee et al. (2011)

Fernandez-Revuelta Perez and Robson (1999)

Finnegan and Ni Longaigh (2002)

Frow et al. (2005)

Frucot and Shearon (1991)

Gencturk and Aulakh (1995)

Giacobbe et al. (2016)

Harzing (2001)

Harzing and Sorge (2003)

Hassel (1991)

Hassel and

Cunningham (1996)

Hassel and

Cunningham (2004)

Hoffjan et al. (2012)

Hoque and Chia (2012)

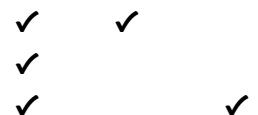

$\checkmark$ US

N.D.

N.D.

M

DE

US JP TW

TW

N.D.

AU

M

DE JP US UK

AU IE SG

Cross

$\checkmark \quad$ DEUKUS

N.D.

Cross

DE UK US

DE UK US

N.D.

N.D.

$\checkmark \quad$ US

M

Europe JP US

PT

Cross

JP US

JP US

$\mathrm{M}$

N.D.

IT

Cross

17 countries IT

Cross

14 countries

BE

Cross

N.D.

BE

Cross

US

N.D.

M

$\checkmark \quad \mathrm{AU}$

$\mathrm{CN}$

Cross

ES

M

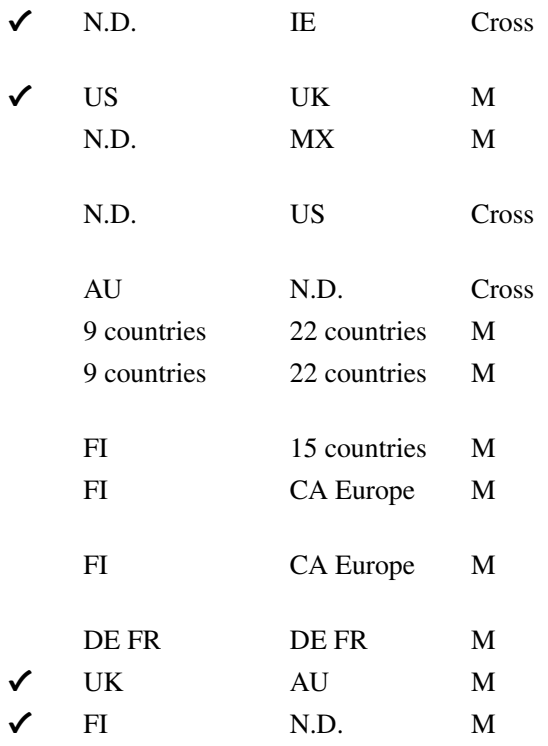




Author/year
Jaussaud and Schaaper
(2006)

Keplinger et al. (2012)

Kihn (2007)

Kihn (2008)

Kihn (2010)

Kranias (2000)

Kraus and Lind (2010)

Lin (2014)

Lovett et al. (2009)

Lowe et al. (2000)

Mahlendorf et al. (2012)

Martinez and Jarillo (1991)

Masquefa (2008)

Moilanen (2007)

Moilanen (2008)

Mongiello and Harris (2006)

Neves and Bugalho (2008)

O'Connor et al. (2011)

O'Donnell (2000)

Paik and Sohn (2004)

Plesner Rossing (2013)

Pudelko and Tenzer (2013)

Quattrone and Hopper (2005)

Richards (2000)

Richards and $\mathrm{Hu}$ (2003)

Roth and O'Donnell (1996)

Schaaper et al. (2011)

Schaeffer et al. (2014)

Seal (2001)

Sheu et al. (2004)

Taylor (1999)

Van der Stede (2003)

Wilkinson et al. (2008)

\section{Quantitative Qualitative Country of Country of \\ headquarters subsidiary \\ Survey Archive Interview Case}

Sector

\section{$\sqrt{ }$}
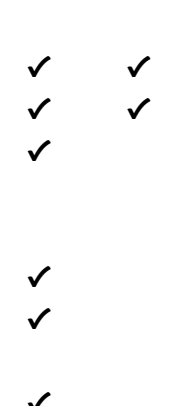

$\sqrt{ }$
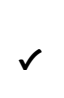


\begin{tabular}{|c|c|c|c|c|c|}
\hline \multirow[t]{2}{*}{ Author/year } & Quantitative & Qualitative & \multirow{2}{*}{$\begin{array}{l}\text { Country of } \\
\text { headquarters }\end{array}$} & \multirow{2}{*}{$\begin{array}{l}\text { Country of } \\
\text { subsidiary }\end{array}$} & \multirow[t]{2}{*}{ Sector } \\
\hline & Survey Archive & Interview Case & & & \\
\hline $\begin{array}{l}\text { Williams and van } \\
\text { Triest (2009) }\end{array}$ & $\checkmark$ & & 15 countries & 18 countries & $\mathrm{S}$ cross \\
\hline Yu et al. (2006) & $\checkmark$ & & TW & 7 countries & Cross \\
\hline
\end{tabular}

2-digit country codes, N.D. = not defined, Sector: $\mathrm{M}=$ manufacturing, $\mathrm{S}=$ services, cross $=$ cross sectional

\section{References}

Abdallah WM, Alnamri M (2015) Non-financial performance measures and the BSC of multinational companies with multi-cultural environment: an empirical investigation. Cross Cult Manag Int J 22:594-607

Al Chen YS, Romocki T, Zuckerman GJ (1997) Examination of U.S.-based Japanese subsidiaries: evidence of the transfer of the Japanese strategic cost management. Int J Account 32:417-440

Al-Husan FB, James P (2003) Cultural control and multinationals: the case of privatized Jordanian companies. Int J Hum Resour Manag 14:1284-1295

Andersson U, Forsgren M (1996) Subsidiary embeddedness and control in the multinational corporation. Int Bus Rev 5:487-508

Anthony RN, Govindarajan V, Hartmann FGH et al (eds) (2014) Management control systems, 1, Europ edn. McGrawHill Education, Higher Education, London

Asel JA, Posch A, Speckbacher G (2011) Squeezing or cuddling? The impact of economic crises on management control and stakeholder management. Rev Manag Sci 5:213-231

Aulakh PS, Gencturk EF (2000) International principal-agent relationships: control, governance and performance. Ind Mark Manag 29:521-538

Avison D, Malaurent J (2007) Impact of cultural differences: a case study of ERP introduction in China. Int J Inf Manag 27:368-374

Baldenius T, Melumad ND, Reichelstein S (2004) Integrating managerial and tax objectives in transfer pricing. Account Rev 79:591-615

Beard V, Al-Rai Z (1999) Collection and transmission of accounting information across cultural borders: the case of US MNEs in Jordan. Int J Account 34:133-150

Björkman A, Piekkari R (2009) Language and foreign subsidiary control: an empirical test. J Int Manag 15:105-117

Blocher EJ, Stout DE, Cokins G (2010) Cost management: a strategic emphasis, 5th edn. McGraw-Hill, Boston (International edition)

Borkowski SC (1999) International managerial performance evaluation: a five country comparison. J Int Bus Stud 30:533-555

Bouncken RB, Gast J, Kraus S, Bogers M (2015) Coopetition: a systematic review, synthesis, and future research directions. Rev Manag Sci 9:577-601

Brenner B, Ambos B (2013) A question of legitimacy? A dynamic perspective on multinational firm control. Organ Sci 24:773-795

Busco C, Giovannoni E, Scapens RW (2008) Managing the tensions in integrating global organisations: the role of performance management systems. Manag Account Res 19:103-125

Carr C, Tomkins C (1996) Strategic investment decisions: the importance of SCM. A comparative analysis of 51 case studies in UK, US and German companies. Manag Account Res 7:199-217

Chang E, Taylor MS (1999) Control in multinational corporations (MNCs): the case of Korean manufacturing subsidiaries. J Manag 25:541-565

Chang YY, Mellahi K, Wilkinson A (2009) Control of subsidiaries of MNCs from emerging economies in developed countries: the case of Taiwanese MNCs in the UK. Int J Hum Resour Manag 20:75-95

Chenhall RH (2003) Management control systems design within its organizational context: findings from contingency-based research and directions for the future. Account Organ Soc 28:127-168 
Chow CW, Shields MD, Wu A (1999) The importance of national culture in the design of and preference for management controls for multi-national operations. Account Organ Soc 24:441-461

Chung LH, Gibbons PT, Schoch HP (2000) The influence of subsidiary context and head office strategic management style on control of MNCs: the experience in Australia. Account Audit Account J 13:647-668

Chung LH, Gibbons PT, Schoch HP (2006) The management of information and managers in subsidiaries of multinational corporations. Br J Manag 17:153-165

Coates JB, Davis EW, Emmanuel CR et al (1992) Multinational companies performance measurement systems: international perspectives. Manag Account Res 3:133-150

Coates J, Davis T, Stacey R (1995) Performance measurement systems, incentive reward schemes and short-termism in multinational companies: a note. Manag Account Res 6:125-135

Cools M, Slagmulder R (2009) Tax-compliant transfer pricing and responsibility accounting. J Manag Account Res 21:151-178

Cools M, Emmanuel C, Jorissen A (2008) Management control in the transfer pricing tax compliant multinational enterprise. Account Organ Soc 33:603-628

Cooper DJ, Ezzamel M (2013) Globalization discourses and performance measurement systems in a multinational firm. Account Organ Soc 38:288-313

Crespo CF, Griffith DA, Lages LF (2014) The performance effects of vertical and horizontal subsidiary knowledge outflows in multinational corporations. Int Bus Rev 23:993-1007

Dent JF (1996) Global competition: challenges for management accounting and control. Manag Account Res 7:247-269

Ding DZ (1997) Control, conflict, and performance: a study of US-Chinese joint ventures. J Int Mark 5:31-45

Dong B, Zou S, Taylor CR (2008) Factors that influence multinational corporations' control of their operations in foreign markets: an empirical investigation. J Int Mark 16:98-119

Dossi A, Patelli L (2008) The decision-influencing use of performance measurement systems in relationships between headquarters and subsidiaries. Manag Account Res 19:126-148

Dossi A, Patelli L (2010) You learn from what you measure: financial and non-financial performance measures in multinational companies. Long Range Plan 43:498-526

Du Y, Deloof M, Jorissen A (2013) Headquarters-subsidiary interdependencies and the design of performance evaluation and reward systems in multinational enterprises. Eur Account Rev 22:391-424

Du Y, Deloof M, Jorissen A (2015) The roles of subsidiary boards in multinational enterprises. J Int Manag 21:169-181

Endenich C, Brandau M, Hoffjan A (2011) Two decades of research on comparative management accounting-achievements and future directions. Aust Account Rev 21:365-382

Epstein MJ, Roy M-J (2007) Implementing a corporate environmental strategy: establishing coordination and control within multinational companies. Bus Strategy Environ 16:389-403

Fee A, McGrath-Champ S, Yang X (2011) Expatriate performance management and firm internationalization: australian multinationals in China. Asia Pac J Hum Resour 49:365-384

Fernandez-Revuelta Perez L, Robson K (1999) Ritual legitimation, de-coupling and the budgetary process: managing organizational hypocrisies in a multinational company. Manag Account Res 10:383-407

Finnegan P, Ni Longaigh S (2002) Examining the effects of information technology on control and coordination relationships: an exploratory study in subsidiaries of pan-national corporations. J Inf Technol 17:149-163

Frow N, Marginson D, Ogden S (2005) Encouraging strategic behaviour while maintaining management control: multi-functional project teams, budgets, and the negotiation of shared accountabilities in contemporary enterprises. Manag Account Res 16:269-292

Frucot V, Shearon WT (1991) Budgetary participation, locus of control, and Mexican managerial performance and job satisfaction. Account Rev 66:80-99

Gencturk EF, Aulakh PS (1995) The use of process and output controls in foreign markets. J Int Bus Stud 26:755-786

Ghoshal S, Bartlett CA (1990) The multinational corporation as an interorganizational network. Acad Manag Rev 15:603-625

Giacobbe F, Matolcsy Z, Wakefield J (2016) An investigation of wholly-owned foreign subsidiary control through transaction cost economics theory. Account Finance 56:1041-1070

Granlund M, Lukka K (1998) It's a small world of management accounting practices. J Manag Account Res 10:153-179 
Harrison GL, McKinnon JL (1999) Cross-cultural research in management control systems design: a review of the current state. Account Organ Soc 24:483-506

Harzing A-W (1999) Managing the multinationals - an international study of control mechanisms. Edward Elgar, Cheltenham

Harzing A-W (2001) Of bears, bumble-bees, and spiders: the role of expatriates in controlling foreign subsidiaries. J World Bus 36:366-379

Harzing AW, Sorge A (2003) The relative impact of country of origin and universal contingencies on internationalization strategies and corporate control in multinational enterprises: worldwide and European perspectives. Organ Stud 24:187-214

Hassel L (1991) Headquarter reliance on accounting performance measures in a multinational context. J Int Financ Manag Account 3:17-38

Hassel LG, Cunningham GM (1996) Budget effectiveness in multinational corporations: an empirical test of the use of budget controls moderated by two dimensions of budgetary participation under high and low environmental dynamism. Manag Int Rev MIR 36:245-266

Hassel LG, Cunningham GM (2004) Psychic distance and budget control of foreign subsidiaries. J Int Account Res 3:79-93

Hoffjan A, Wömpener A (2006) Comparative analysis of strategic management accounting in German and English-language general management accounting textbooks. Schmalenbach Bus Rev SBR 58:234-258

Hoffjan A, Trapp R, Endenich C, Boucoiran T (2012) International budgeting — challenges for GermanFrench companies. J Manag Control 23:5-25

Hofstede G (2001) Cultures consequences. Comparing values, behaviours, institutions and organisations across nations, vol 2. Sage, Thousand Oaks

Hopper T, Tsamenyi M, Uddin S, Wickramasinghe D (2009) Management accounting in less developed countries: what is known and needs knowing. Account Audit Account J 22:469-514

Hoque Z, Chia M (2012) Competitive forces and the levers of control framework in a manufacturing setting: a tale of a multinational subsidiary. Qual Res Account Manag 9:123-145

Horngren CT, Datar SM, Rajan MV (2012) Cost accounting: a managerial emphasis, 14th edn. Pearson/ Prentice Hall, Upper Saddle River

Hyvönen T, Järvinen J, Pellinen J (2008) A virtual integration-the management control system in a multinational enterprise. Manag Account Res 19:45-61

Jaussaud J, Schaaper J (2006) Control mechanisms of their subsidiaries by multinational firms: a multidimensional perspective. J Int Manag 12:23-45

Jensen MC, Meckling WH (1976) Theory of the firm: managerial behavior, agency costs and ownership structure. J Financ Econ 3:305-360

Keplinger K, Feldbauer-Durstmueller B, Mitter C (2012) Management accounting practices in a multicultural environment: evidence from Austria, Russia and the US. Int J Strateg Manag 12:37-49

Kihn L-A (2007) Financial consequences in foreign subsidiary manager performance evaluations. Eur Account Rev 16:531-554

Kihn L-A (2008) The determinants of multiple forms of controls in foreign subsidiary manager evaluations. Int J Account Audit Perform Eval 5:157-182

Kihn L-A (2010) An empirical investigation of the principal top management styles in the emphasis of multiple forms of controls. Int J Account Audit Perform Eval 6:108-127

Kostova T, Marano V, Tallman S (2016) Headquarters-subsidiary relationships in MNCs: fifty years of evolving research. J World Bus 51:176-184

Kranias DS (2000) Cultural control: the case of Japanese multinational companies and their subsidiaries in the UK. Manag Decis 38:638-648

Kraus K, Lind J (2010) The impact of the corporate balanced scorecard on corporate control—a research note. Manag Account Res 21:265-277

Kuttner M, Feldbauer-Durstmueller B (2016) Comparative management accounting in developing countries - state-of-the-art and future perspectives. Int J Bus Res 16:81-104

Lin L-H (2014) Subsidiary performance: the contingency of multinational corporation's international strategy. Eur Manag J 32:928-937

Lovett SR, Perez-Nordtvedt L, Rasheed AA (2009) Parental control: a study of US subsidiaries in Mexico. Int Bus Rev 18:481-493

Lowe J, Morris J, Wilkinson B (2000) British factory, Japanese factory and Mexican factory: an international comparison of front-line management and supervision. J Manag Stud 37:541-562 
Mahlendorf MD, Rehring J, Schäffer U, Wyszomirski E (2012) Influencing foreign subsidiary decisions through headquarter performance measurement systems. Manag Decis 50:688-717

Malmi T, Brown DA (2008) Management control systems as a package-opportunities, challenges and research directions. Manag Account Res 19:287-300

Martinez JI, Jarillo JC (1991) Coordination demands of international strategies. J Int Bus Stud $22: 429-444$

Masquefa B (2008) Top management adoption of a locally driven performance measurement and evaluation system: a social network perspective. Manag Account Res 19:182-207

Merchant KA, Otley DT (2007) A review of the literature on control and accountability. In: Chapman C, Hopwood A, Shields M (eds) Handbook of management accounting research. Elsevier, Amsterdam, pp 785-802

Merchant KA, Van der Stede WA (2017) Management control systems: performance measurement, evaluation and incentives, 4th edn. Pearson, Harlow

Mitter C, Duller C, Feldbauer-Durstmüller B, Kraus S (2014) Internationalization of family firms: the effect of ownership and governance. Rev Manag Sci 8:1-28

Moilanen S (2007) Knowledge translation in management accounting and control: a case study of a multinational firm in transitional economies. Eur Account Rev 16:757-789

Moilanen S (2008) The role of accounting and an intermediate subsidiary in the management control system. Manag Account Res 19:252-269

Mongiello M, Harris P (2006) Management accounting and corporate management: insights into multinational hotel companies. Int J Contemp Hosp Manag 18:364-379

Neves JC, Bugalho A (2008) Coordination and control in emerging international construction firms. Constr Manag Econ 26:3-13

O'Connor NG, Vera-Muñoz SC, Chan F (2011) Competitive forces and the importance of management control systems in emerging-economy firms: the moderating effect of international market orientation. Account Organ Soc 36:246-266

O'Donnell SW (2000) Managing foreign subsidiaries: agents of headquarters, or an interdependent network? Strateg Manag J 21:525-548

Otley D (2016) The contingency theory of management accounting and control: 1980-2014. Manag Account Res 31:45-62

Paik Y, Sohn JD (2004) Expatriate managers and MNC's ability to control international subsidiaries: the case of Japanese MNCs. J World Bus 39:61-71

Plesner Rossing C (2013) Tax strategy control: the case of transfer pricing tax risk management. Manag Account Res 24:175-194

Pudelko M, Tenzer H (2013) Subsidiary control in Japanese, German and US multinational corporations: direct control from headquarters versus indirect control through expatriation. Asian Bus Manag 12:409-431

Quattrone P, Hopper T (2005) A 'time-space odyssey': management control systems in two multinational organisations. Account Organ Soc 30:735-764

Richards M (2000) Control exercised by US multinationals over their overseas affiliates: does location make a difference? J Int Manag 6:105-120

Richards M, Hu MY (2003) US subsidiary control in Malaysia and Singapore. Bus Horiz 46:71-76

Roth K, O'Donnell S (1996) Foreign subsidiary compensation strategy: an agency theory perspective. Acad Manag J 39:678-703

Sageder M, Mitter C, Feldbauer-Durstmüller B (2018) Image and reputation of family firms: a systematic literature review of the state of research. Rev Manag Sci 12:335-377

Schaaper J, Mizoguchi S, Nakamura H, Yamashita S (2011) Control of French and Japanese subsidiaries in China: implementing control mechanisms before and after the global economic crisis. Asia Pac Bus Rev 17:411-430

Schaeffer U, Mahlendorf MD, Rehring J (2014) Does the interactive use of headquarter performance measurement systems in foreign subsidiaries endanger the potential to profit from local relationships? Aust Account Rev 24:21-38

Seal W (2001) Management accounting and the challenge of strategic focus. Manag Account Res 12:487-506

Senftlechner D, Hiebl MRW (2015) Management accounting and management control in family businesses: past accomplishments and future opportunities. J Account Organ Change 11:573-606

Sheu C, Chae B, Yang C-L (2004) National differences and ERP implementation: issues and challenges. Omega 32:361-371 
Taylor B (1999) Patterns of control within Japanese manufacturing plants in China: doubts about Japanization in Asia. J Manag Stud 36:853-873

Tranfield D, Denyer D, Smart P (2003) Towards a methodology for developing evidence-informed management knowledge by means of systematic review. Br J Manag 14:207-222

Trompenaars F, Hampden-Turner C (2012) Riding the waves of culture-understanding diversity in global business, vol 3. N. Brealey Publishing, London

Van der Stede WA (2003) The effect of national culture on management control and incentive system design in multi-business firms: evidence of intracorporate isomorphism. Eur Account Rev 12:263-285

Wilkinson TJ, Peng GZ, Brouthers LE, Beamish PW (2008) The diminishing effect of cultural distance on subsidiary control. J Int Manag 14:93-107

Williams C, van Triest S (2009) The impact of corporate and national cultures on decentralization in multinational corporations. Int Bus Rev 18:156-167

Yiu D, Makino S (2002) The choice between joint venture and wholly owned subsidiary: an institutional perspective. Organ Sci 13:667-683

Yu C-MJ, Wong H-C, Chiao Y-C (2006) Local linkages and their effects on headquarters' use of process controls. J Bus Res 59:1239-1247 